\title{
Comparative transcriptomics of the model mushroom Coprinopsis cinerea reveals tissue-specific armories and a conserved circuitry for sexual development
}

David Fernando Plaza, Chia-Wei Lin, Niels Sebastiaan Johannes van der Velden, Markus Aebi and Markus Künzler*

\begin{abstract}
Background: It is well known that mushrooms produce defense proteins and secondary metabolites against predators and competitors; however, less is known about the correlation between the tissue-specific expression and the target organism (antagonist) specificity of these molecules. In addition, conserved transcriptional circuitries involved in developing sexual organs in fungi are not characterized, despite the growing number of gene expression datasets available from reproductive and vegetative tissue. The aims of this study were: first, to evaluate the tissue specificity of defense gene expression in the model mushroom Coprinopsis cinerea and, second, to assess the degree of conservation in transcriptional regulation during sexual development in basidiomycetes.
\end{abstract}

Results: In order to characterize the regulation in the expression of defense loci and the transcriptional circuitries controlling sexual reproduction in basidiomycetes, we sequenced the poly (A)-positive transcriptome of stage 1 primordia and vegetative mycelium of $C$. cinerea A43mutB43mut. Our data show that many genes encoding predicted and already characterized defense proteins are differentially expressed in these tissues. The predicted specificity of these proteins with regard to target organisms suggests that their expression pattern correlates with the type of antagonists these tissues are confronted with. Accordingly, we show that the stage 1 primordium-specific protein CC1G_11805 is toxic to insects and nematodes. Comparison of our data to analogous data from Laccaria bicolor and Schizophyllum commune revealed that the transcriptional regulation of nearly 70 loci is conserved and probably subjected to stabilizing selection. A Velvet domain-containing protein was found to be up-regulated in all three fungi, providing preliminary evidence of a possible role of the Velvet protein family in sexual development of basidiomycetes. The PBS-soluble proteome of $C$. cinerea primordia and mycelium was analyzed by shotgun LC-MS. This proteome data confirmed the presence of intracellular defense proteins in primordia.

Conclusions: This study shows that the exposure of different tissues in fungi to different types of antagonists shapes the expression pattern of defense loci in a tissue-specific manner. Furthermore, we identify a transcriptional circuitry conserved among basidiomycetes during fruiting body formation that involves, amongst other transcription factors, the up-regulation of a Velvet domain-containing protein.

Keywords: Fungal defense, Sexual development, C. cinerea, Primordia, RNA-seq, Comparative transcriptomics, Tissue-specific LC-MS proteome

\footnotetext{
* Correspondence: markus.kuenzler@micro.biol.ethz.ch

Department of Biology, Institute of Microbiology, ETH Zürich, Zürich,

Switzerland
} 


\section{Background}

The last eukaryotic common ancestor (LECA) was facultatively sexual and evolved nearly 1.5 billion years ago in the Proterozoic eon [1]. Sexual reproduction (SR) shares common features across the eukaryotic lineage such as ploidy changes, meiotic recombination and cell-cell recognition between gametes followed by cellular fusion and zygote formation [2]. An increase in the genetic diversity of the population, making it more adaptable to changing environmental conditions, as well as the dilution of deleterious mutations out of the gene pool are the most remarkable evolutionary innovations achieved by SR [3]. Despite all these clear benefits, sex is energetically expensive and entails a higher chance of genetic and organelle conflicts [2].

During sexual reproduction, fungi undergo dramatic morphological changes driven by environmental conditions such as light, nutrient availability and grazing by predators [4]. In basidiomycetes, mushroom development starts with intense localized hyphal branching leading to the formation of hyphal knots. These branching hyphae further aggregate to form 1-2 mm secondary nodules where cell differentiation leads to the establishment of bipolar primordia containing all the tissues observed in the mature fruiting body [5]. As a last step, primordia develop to mature fruiting bodies mainly by cellular expansion [6]. Due to their hyphal density, primordia and fruiting bodies are attractive to predators including mollusks, arthropods and nematodes [4].

Coprinopsis cinerea has been used as a model basidiomycete since the mid-1950s [7] due to its saprobic lifestyle, its rapid growth and the feasibility of producing fruiting bodies under defined laboratory conditions [6]. In nature, $C$. cinerea grows on horse dung [6], a eutrophic substrate rich in competing microorganisms, such as Firmicutes, Bacteroidetes and Proteobacteria [8]. The recent sequencing of the $C$. cinerea genome [9] allows the study of this organism gene expression on transcriptome and proteome level at different developmental stages or under a variety of environmental settings.

Morphological changes and environmental signals during fruiting body formation in C. cinerea are well described [6]; nonetheless, comparably little is known about the molecular machinery driving sexual reproduction processes in this basidiomycete. Recently, mutations blocking fruiting body development at different stages or altering mushroom morphology were identified [10-15]. In addition, $d s t 2$ and $d s t 1$, encoding a blue-light photoreceptor and a flavin adenine dinucleotide-binding protein, were shown to play a role in blue light sensing. In agreement with previous experiments, strains defective in these two proteins were unable to form fruiting bodies, showing that blue light is an essential environmental trigger of mushroom development [16]. Most recently, C. cinerea strains carrying mutations in the putative component of the SWI/SNF chromatin remodeling complex snf5 (CC1G_15539) were shown to be defective in fruiting initiation, suggesting that epigenetic reprogramming of loci occurs during fruiting body formation [17].

Aerial fruiting bodies are an attractive prey for predators and thus are protected by a battery of defense molecules (toxins) including proteins [18-21], peptides [22] and secondary metabolites [23-25]. Some of these toxins are known to be specifically produced in the fruiting body and not in the vegetative mycelium $[26,27]$. For instance, cytoplasmic lectins showing a broad range of non-self-carbohydrate specificities, also referred to as fruiting body lectins due to their specific expression pattern, have been shown to exert toxicity to nematodes, insect larvae and amoeba [18]. Protein-mediated inhibition of serine proteases [20], proteolytic degradation of predator-derived proteins $[28,29]$ and sequestration of biotin [19] are other strategies of basidiomycetous fruiting bodies to dissuade predators. Vegetative mycelium, in contrast, digests extracellular carbon macromolecules in the growth substrate, such as cellulose and lignin, into smaller degradation products which are absorbed by the growing hyphae. At the same time, these smaller molecules become available for competing bacteria that profit from the fungal enzymatic machinery [30]. As a response to bacterial competitors, fungi have evolved secreted antimicrobial proteins. Mygind and colleagues presented recent evidence that vegetative mycelia of fungi secrete cysteine-stabilized antibacterial peptides which play a role in the arms race with competing bacteria [31].

Using RNA-seq in C. cinerea, we show evidence suggesting a role of the Velvet protein regulon in sexual development of basidiomycetes. Our data supports the existence of a conserved transcriptional circuitry in basidiomycetes fruiting bodies consisting of at least 60 orthologous genes probably involved in mushroom development and function. In addition, our data reveals the existence of two different sets of fungal defense proteins in vegetative and sexual organs matching the type of competitors and predators by which these structures are challenged in nature. The transcriptome data is supported by the first partial shotgun mass spectrometry catalog of proteins present in $C$. cinerea stage 1 primordia (S1P) and vegetative mycelium (VM).

\section{Results}

Differential gene expression during fruiting body development in C. cinerea

Four different cDNA libraries were sequenced with a final $7.32 \mathrm{~Gb}$ mapped data output. Approximately 95\% of the open reading frames (ORFs) in the genome of 
C. cinerea $\mathrm{A} 43$ mutB43mut $(\mathrm{AB})$ were transcribed using five reads/ORF as the minimal threshold for a locus to be considered as expressed (Table 1). Differential gene expression at the RNA level between S1P and VM was examined (Additional file 1: Table S1). Eleven percent of the annotated ORFs in the $C$. cinerea genome were found to be differentially expressed, 795 (6\%) and 679 loci (5\%) in VM and S1P, respectively, using fold change 8 and Fisher's exact test p-value $\leq 0.05$ as thresholds (Figure 1, Additional file 2: Table S2). The number of differentially transcribed loci in these two developmental stages increased to 2522 in VM and 3209 in S1P when a fold change threshold of 2 was set, corresponding to approximately $45 \%$ annotated ORFs in the genome of C. cinerea.

To validate these data, qRT-PCR of four selected loci (CC1G_10318, CC1G_09480, CC1G_05299 and CC1G_ 11805) was performed. Although S1P/VM expression ratios did not exactly match those observed by RNA-seq, qRT-PCR results showed the same trend of differential gene expression for these loci during $C$. cinerea development as observed by SOLiD RNA-seq (Additional file 3: Figure S1). In addition, we verified that the expression values of reported housekeeping loci commonly used in qRT-PCR normalization were in a range indicative of constitutive expression $(-2 \leq \log 2(\mathrm{~S} 1 \mathrm{P} / \mathrm{VM}) \leq 2)$ (Additional file 4: Table S3).

Enrichment of PSI-BLAST-derived functional annotation terms was visualized using Wordle (๑ IBM Corporation) [32] after excluding frequent non-informative terms. By far, the most commonly assigned annotation term was "hypothetical protein" in S1P (275 loci) and VM (426 loci); nonetheless, there was a significant enrichment of $\mathrm{N}$-methyltransferase (histone-lysine $\mathrm{N}$ methyltransferase) tags in S1P (7 loci). Enrichment of functional annotation terms also shows that different sets of cytochromes, kinases, dehydrogenases, transporters and hydrophobins are specifically expressed in vegetative mycelium or young fruiting bodies (Figure 1). Functional annotation clustering using DAVID Bioinformatics Resources 6.7 [33] confirmed the enrichment of

Table 1 General features of the $C$. cinerea S1P and VM transcriptomes

\begin{tabular}{lccc}
\hline & \multicolumn{3}{c}{ Library size (reads) } \\
\cline { 2 - 4 } & $\begin{array}{c}\text { Biological } \\
\text { replicate 1 }\end{array}$ & $\begin{array}{c}\text { Biological } \\
\text { replicate 2 }\end{array}$ & Expression (\%)* \\
\hline S1P & 26243754 & 25653679 & 95.55 \\
VM & 29374279 & 23269631 & 95.13 \\
& Average SOLiD read size (b) & 70 & \\
& Sequenced material (Gb) & 7.32 & \\
\hline
\end{tabular}

*Mean percentage of annotated ORFs detected to be expressed using a minimal threshold 5 reads/ORF. protein methyltransferases and hydrophobins in S1P with 11 and 6 fold enrichment compared to the occurrence of these functional categories in the genome of $C$. cinerea (Additional file 5: Table S4).

\section{Tissue-specific expression of $C$. cinerea defense proteins}

Several cytoplasmic defense lectins and protease inhibitors such as C. cinerea lectin 2 (CCL2, CC1G_11781) [34], Coprinopsis galectin 1 (CGL1, CC1G_05003) [35] and two paralogous serine protease inhibitors from Coprinopsis (Cospin; CC1G_09479 and CC1G_09480) [20] were found to be highly up-regulated in C. cinerea S1P (Table 2). Out of these previously characterized genes coding for proteins with nematotoxic and insecticidal activity, Cospin and CCL2 were found to be among the top 50 most highly transcribed and differentially expressed loci in S1P. Among these, two loci, CC1G_ 10318 and CC1G_11805, encoding homologous proteins with a predicted aerolysin/ETX pore-forming domain as well as loci encoding proteins with suspected antibacterial and antifungal function including two peptidoglycan binding proteins, the toxin component of a bacterial toxin-antitoxin system and a Thaumatin-like protein were found. In contrast to S1P-specific defense proteins, defense proteins specifically up-regulated in VM were mainly secreted. These proteins included three putative lysozymes, several proteins containing a CFEM domain (PF05730) whose structure resembles cysteine-stabilized antibacterial peptides, and two representatives of the cerato-platanin family of secreted proteins (Table 3). Latter protein family is expanded in basidiomycetes and has recently been implicated in interactions of dikaryotic fungi with other organisms [36,37]. During sexual development on herbivore dung, C. cinerea is exposed to a succession of antagonists (predators and competitors) colonizing this substrate. The differential expression of cytoplasmic and secreted defense proteins in S1P and $\mathrm{VM}$, respectively, might reflect the prevalent types of antagonists with which these tissues of $C$. cinerea are confronted.

\section{The S1P-specific aerolysin/ETX pore-forming}

domain-containing protein CC1G_11805 is toxic to nematode and insect larvae

CC1G_11805, CC1G_10318 and CC1G_08369 encode three homologous $30-40 \mathrm{kDa}$ proteins containing a predicted aerolysin/ETX pore-forming domain (Figure 2A). This domain is homologous to the one present in the insecticidal epsilon toxin (ETX) from Clostridium perfringens [38] and distantly related to aerolysin pore-forming toxins [39]. In order to test the significance of the upregulation of CC1G_11805 and CC1G_10318 in S1P with regard to fungal defense, we cloned and recombinantly expressed CC1G_11805 in Escherichia coli and 


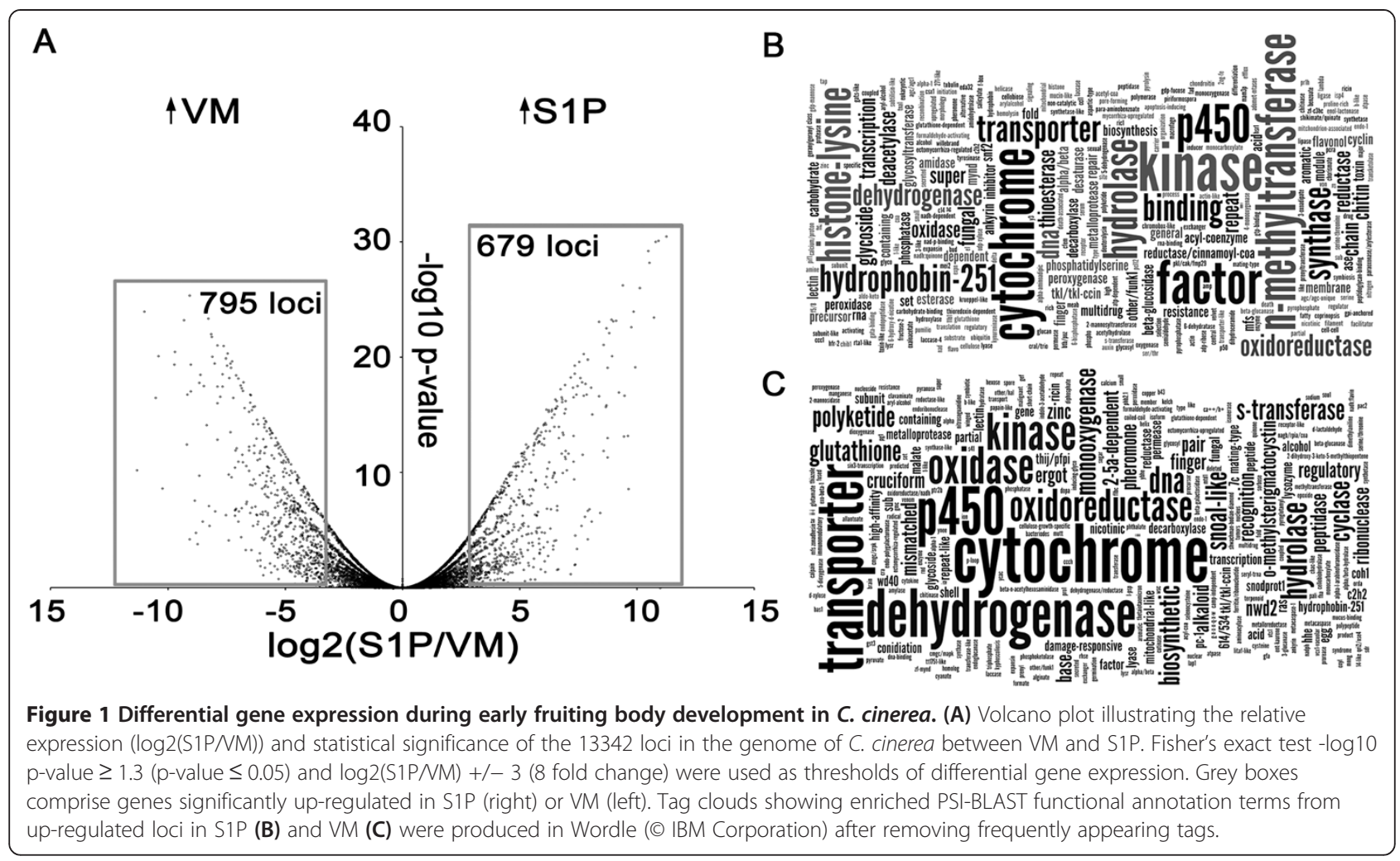

Table 2 S1P-specific defense loci

\begin{tabular}{|c|c|c|c|c|c|}
\hline Locus & Fold S1P/VM & Functional annotation & *p-value & †SignalP & ‡TMHMM \\
\hline CC1G_09480 & 2426 & Cospin1 & $1.26 \mathrm{E}-305$ & $\mathrm{~N}$ & $\mathrm{~N}$ \\
\hline CC1G_11781 & 1939 & $\mathrm{CCL} 2$ & 4.64E-302 & N & N \\
\hline CC1G_09479 & 692 & Cospin2 & $2.38 \mathrm{E}-132$ & $N$ & N \\
\hline CC1G_12219 & 237 & Related to Velvet A protein & $6.42 \mathrm{E}-43$ & N & N \\
\hline CC1G_07937 & 83 & Ricin B-fold protein & $1.08 \mathrm{E}-148$ & Y & N \\
\hline CC1G_11778 & 69 & CCL1 & 7.80E-137 & N & N \\
\hline CC1G_10318 & 68 & Pore-forming protein & $8.08 \mathrm{E}-91$ & $\mathrm{~N}$ & N \\
\hline CC1G_07956 & 66 & Peptidoglycan-binding domain 1 protein & $1.70 \mathrm{E}-48$ & Y & 1 \\
\hline CC1G_14321 & 35 & Hemolysin & $9.81 \mathrm{E}-77$ & N & 3 \\
\hline CC1G_08484 & 34 & Cercosporin toxin biosynthesis protein & 4.71E-115 & N & N \\
\hline CC1G_06959 & 31 & Thaumatin-like protein & $3.50 \mathrm{E}-79$ & Y & N \\
\hline CC1G_13099 & 15 & Peptidoglycan-binding domain 1 protein & 4.40E-17 & N & N \\
\hline CC1G_05003 & 12 & CGL1 & 7.13E-37 & N & N \\
\hline CC1G_11123 & 11 & Toxin-antitoxin system, toxin component & 1.84E-33 & N & $\mathrm{N}$ \\
\hline CC1G_11246 & 11 & Ricin B-fold protein & 7.70E-28 & Y & N \\
\hline CC1G_11805 & 11 & Pore-forming protein & $1.69 \mathrm{E}-40$ & $\mathrm{~N}$ & N \\
\hline
\end{tabular}

*Fisher's exact test.

$+\mathrm{N}$ or $\mathrm{Y}$ indicates the lack or presence of a signal peptide.

$\ddagger \mathrm{N}$ indicates a lack of transmembrane helices, while a number corresponds to the amount of transmembrane helices predicted in the ORF. 
Table 3 VM-specific defense loci

\begin{tabular}{|c|c|c|c|c|c|}
\hline Locus & Fold VM/S1P & PSI Blast & *p-value & †SignalP & ‡TMHMM \\
\hline CC1G_05299 & 2076 & Ricin B-fold protein & 2.95E-240 & $N$ & N \\
\hline CC1G_10614 & 1481 & CFEM domain-containing protein & $9.18 \mathrm{E}-166$ & Y & N \\
\hline CC1G_15645 & 851 & CFEM domain-containing protein & 1.51E-194 & Y & N \\
\hline CC1G_09154 & 639 & Cerato-platanin protein & $6.24 \mathrm{E}-233$ & Y & N \\
\hline CC1G_13813 & 527 & CFEM domain-containing protein & $6.90 \mathrm{E}-195$ & Y & N \\
\hline CC1G_05638 & 67 & Peptidoglycan-binding domain 1 protein & 1.19E-119 & Y & 1 \\
\hline CC1G_05246 & 42 & Ricin B-fold protein & $7.71 \mathrm{E}-125$ & Y & N \\
\hline CC1G_09155 & 24 & Cerato-platanin protein & $3.27 \mathrm{E}-75$ & Y & N \\
\hline CC1G_09421 & 21 & Terpenoid synthase & $5.98 \mathrm{E}-27$ & N & N \\
\hline CC1G_11847 & 17 & Lysozyme & 2.00E-08 & Y & $N$ \\
\hline CC1G_08066 & 16 & Ricin B-fold protein & $1.01 \mathrm{E}-45$ & Y & N \\
\hline CC1G_08310 & 13 & Lysozyme & $6.90 \mathrm{E}-09$ & Y & N \\
\hline CC1G_15739 & 10 & Ricin B-fold protein & $1.54 \mathrm{E}-59$ & Y & N \\
\hline CC1G_03046 & 8 & Lysozyme & 3.68E-05 & Y & $N$ \\
\hline
\end{tabular}

*Fisher's exact test.

$\dagger \mathrm{N}$ or $\mathrm{Y}$ indicates the lack or presence of a signal peptide.

$\mp \mathrm{N}$ indicates a lack of transmembrane helices, while a number corresponds to the amount of transmembrane helices predicted in the ORF.

assessed the toxicity of the protein by feeding the recombinant bacteria to nematode and insect larvae as described previously [40]. Results in Figure 2B show that CC1G_11805 was expressed in soluble form in E. coli. Feeding of CC1G_11805-expressing bacteria to L2 larvae of the mosquito Aedes aegypti lead to their death after $96 \mathrm{~h}$ (Figure 2C). Vector control-containing and fungal lectin-expressing $E$. coli were used as negative and positive controls, respectively, in these experiment $[18,29]$. Similarly, feeding of CC1G_11805-expressing bacteria was found to significantly impair larval development of the $C$. elegans N2 wildtype and pmk-1(km25) mutant strains (Figure 2D); in agreement with the previously reported higher susceptibility of latter strain to different kinds of abiotic and biotic stresses including other nematotoxic fungal defense proteins [35], CC1G_11805 was shown to be more toxic to C. elegans pmk-1(km25) than to N2. These results support previous observations [18] showing that the expression of defense proteins directed against nematodes and insects is significantly increased in C. cinerea sexual organs.

\section{Differential expression of loci involved in sexual development of filamentous fungi}

Various genes were recently described as playing a role at different stages of fruiting body formation of $C$. cinerea [10-17]. With the exception of the cyclopropane fatty acid synthase $c f s 1$, none of these loci were found to be differentially transcribed during $C$. cinerea sexual development (Table 4, Additional file 6: Figure S2). The Velvet protein regulon plays a major role in the control of sexual vs. asexual development in the ascomycete
Aspergillus nidulans [41,42]; therefore, we took a closer look at the expression pattern of $C$. cinerea orthologs of the Velvet protein family and the proteins regulated by it $[41,42]$. CC1G_12219, a Velvet domain-containing protein bearing an NLS is highly induced in S1P (S1P/VM = 237). In total, three out of six Velvet domain-containing proteins encoded in the $C$. cinerea genome (CC1G_12219, CC1G_06962 and CC1G_14883) were found to be developmentally regulated (Additional file 7: Figure S3). Among the other members of the Velvet protein regulon, two homologs of the VeA-regulated activator NsdD (CC1G_ 06391 and CC1G_06265) were also up-regulated in S1P ( $\mathrm{S} 1 \mathrm{P} / \mathrm{VM}=14$ and 2.4, respectively). Moreover, the $C$. cinerea homeodomain transcription factor STE-12 (CC1G_ 02207) showed a moderate up-regulation in primordia (S1P/VM = 2). Finally, CC1G_07060, an ortholog of the $A$. nidulans repressor of sexual development $\operatorname{ros} A$, was 34 fold up-regulated in VM compared to S1P. Taken together, the differential expression of several members of the Velvet protein regulon suggests that these genes may play a role in sexual development of basidiomycetes.

\section{Conserved transcriptional circuitry during fruiting body development among basidiomycetous fungi}

In order to explore a hypothetical conserved gene expression circuitry during the formation of SR structures in basidiomycetes, a comparative transcriptomic analysis by hierarchical clustering including C. cinerea, S. commune [43] and L. bicolor [44] was performed. Orthologous genes in S. commune and L. bicolor were assigned from a PSI-BLAST search (hits with the lowest Evalue $\leq 0.005)$ to 446 and 378 up- and down-regulated 


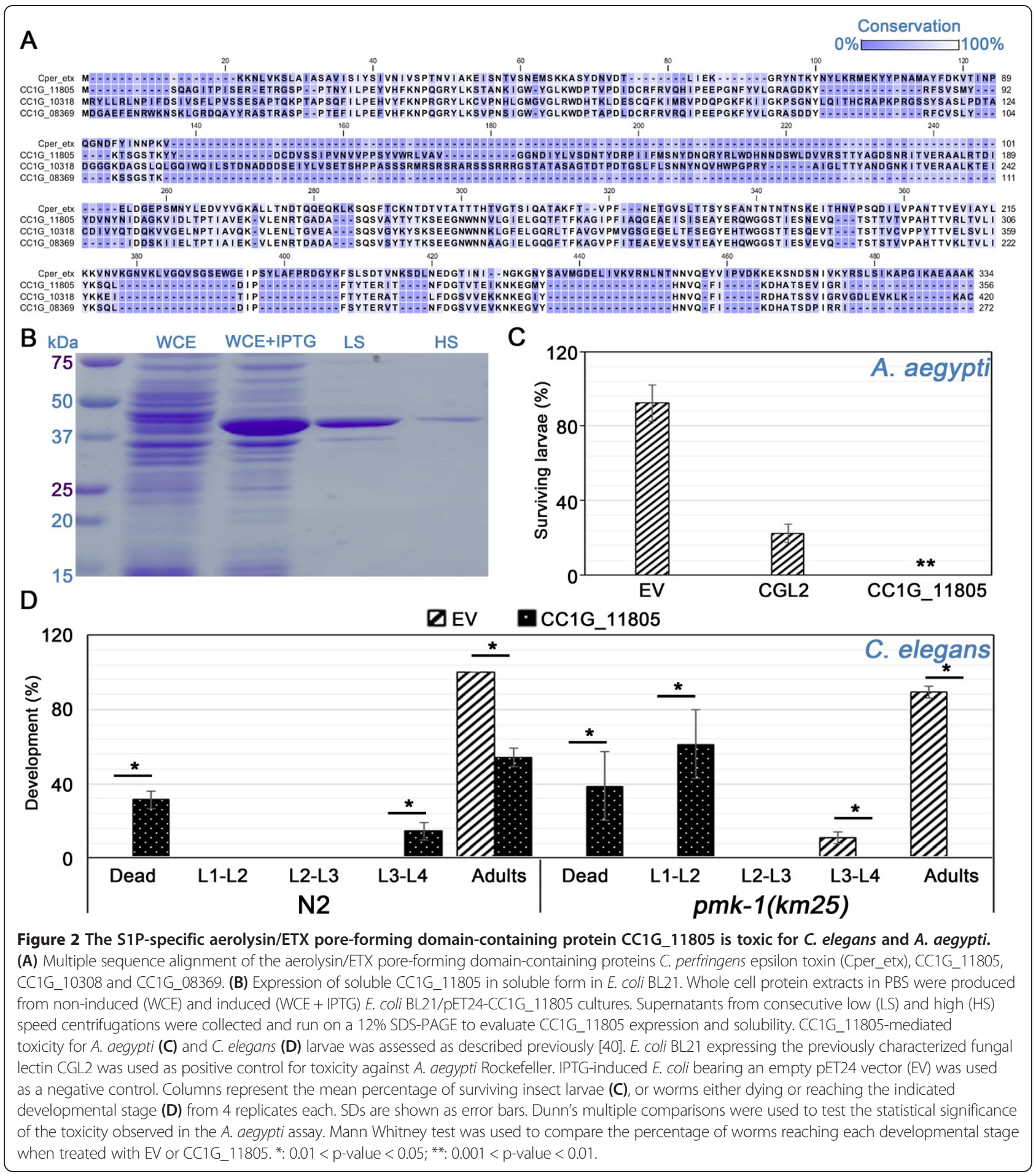

loci in C. cinerea S1P, respectively. Massively parallel signature sequencing tags/million from $S$. commune monokaryotic mycelium and stage 1 primordia $(S c S 1 P)$; as well as $L$. bicolor free-living monokaryotic mycelium (2 replicates) and young fruiting bodies (LbYFB, one replicate) robust multichip average values were retrieved from original studies $[43,44]$. $\log 2$ expression ratios were calculated using monokaryotic mycelium expression values from these conserved loci as denominators and a centroid linkage hierarchical clustering analysis was computed (Figure 3; Additional file 8: Table S5). Four clusters corresponding to 37 up-regulated loci in early 
Table 4 Most genes necessary for fruiting body formation in C. cinerea are not up-regulated in S1P

\begin{tabular}{lcllll}
\hline Locus & Fold S1P/VM & Gene & *p-value & Mutant phenotype & Reference \\
\hline CC1G_03287 & 0.8 & rmt1 & $1.43 \mathrm{E}-01$ & No clamp connections & Nakazawa [15] \\
CC1G_00975 & 1.4 & $u b c 2$ & $1.75 \mathrm{E}-02$ & No hyphal knot formation & Nakazawa 2011 \\
CC1G_15539 & 1.1 & snf5 & $3.98 \mathrm{E}-01$ & Blocked at hyphal knot & Ando [17] \\
CC1G_11387 & 64.0 & $c f 51$ & $5.25 \mathrm{E}-142$ & Blocked at initials & Liu [10] \\
CC1G_06825 & 1.2 & $d s t 2$ & $9.66 \mathrm{E}-02$ & Blocked at stage 2 primordia & Kamada [16] \\
CC1G_08609 & 2.6 & $d s t 1$ & $1.21 \mathrm{E}-13$ & Blocked at stage 2 primordia & Kamada [16] \\
CC1G_10193 & 1.5 & eln3 & $1.40 \mathrm{E}-03$ & Blocked at immature mushroom & Arima [11] \\
CC1G_04713 & 2.3 & eln3 & $5.18 \mathrm{E}-08$ & Blocked at immature mushroom & Arima [11] \\
CC1G_06451 & 2.5 & eln3 & $9.03 \mathrm{E}-13$ & Blocked at immature mushroom & Arima [11] \\
CC1G_01334 & 0.8 & exp1 & $3.65 \mathrm{E}-02$ & Blocked before mushroom decay & Muraguchi [12] \\
\hline
\end{tabular}

*Fisher's exact test.

sexual development in basidiomycetes were identified (Pearson correlation coefficients: 0.95, 0.99, 0.99 and 0.99 , respectively). In addition, two different gene groups (29 loci) were found to be down-regulated in early stages of fruiting body formation when compared to vegetative mycelium of the three species (Pearson correlation coefficients: 0.99 and 0.94, respectively) (Table 5).

This hierarchical clustering approach of gene expression in orthologous loci during sexual development showed that loci involved in core meiotic functions, such

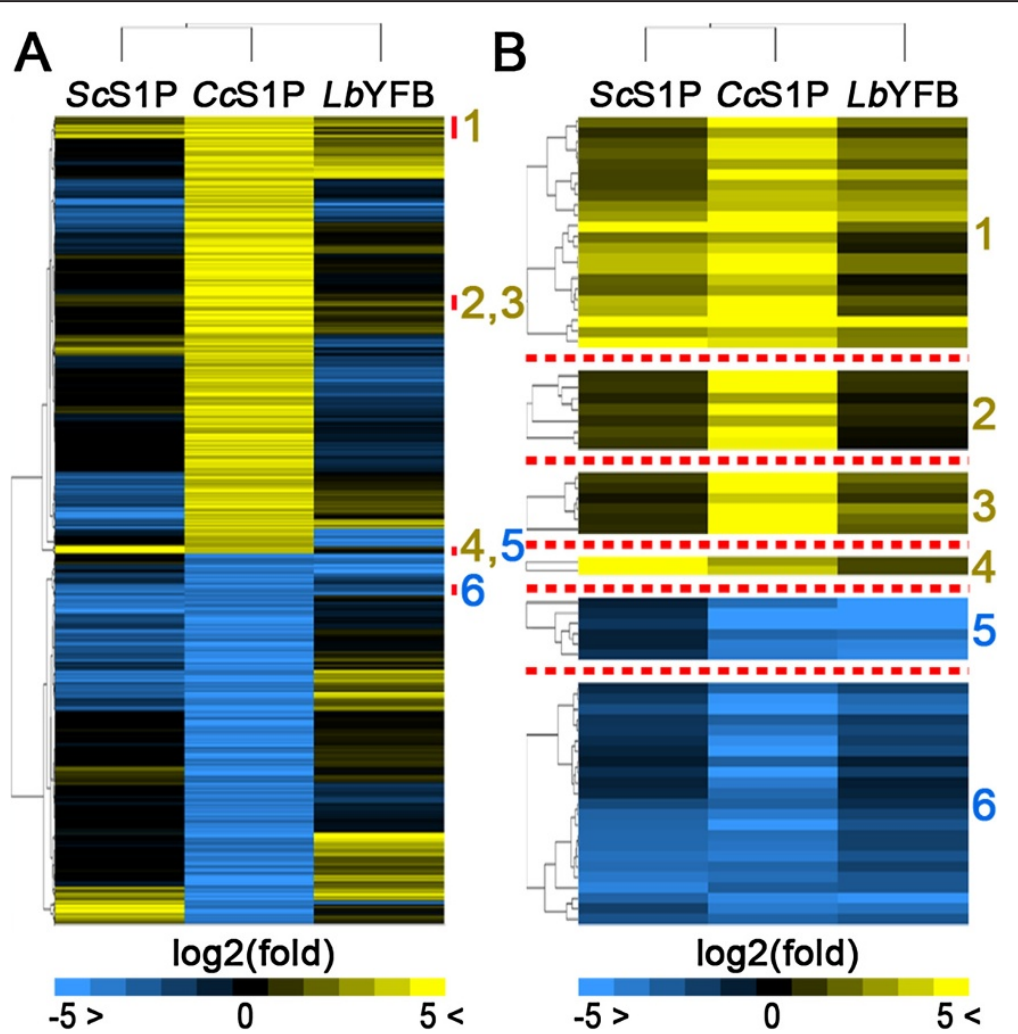

Figure 3 Conserved expression pattern of some gene clusters during fruiting body formation among three different basidiomycetous species. Comparative transcriptome analysis of early sexual development in S. commune 4-39/4-40, C. cinerea AB and L. bicolor S238N-H82 was performed. Orthologous genes (best PSI-BLAST hits with E-values $\leq 0.005$ ) to only 446 and 378 up- and down-regulated loci in S1P, respectively, were found in S. commune 4-39/4-40 and L. bicolor S238N-H82. (A) Fruiting body transcriptome data were retrieved in the form of log2 ratios for these loci from the raw data sets and analyzed by centroid-linkage hierarchical clustering. The red sidelines mark the presence of 6 loci clusters which are consistently up (1-4)- or down (5 and 6)-regulated in young fruiting bodies (YFB) and stage 1 primordia (S1P) of the three species compared. (B) Close-up view of the up- and down-regulated clusters highlighted by red bars in (A). Orthologous genes in C. cinerea, S. commune and L. bicolor corresponding to the numbered clusters, as well as the functional annotation of these loci and the cluster-associated Pearson correlation coefficients can be found in Table 5. 
Table 5 Up- and down-regulation of orthologous loci is conserved in stage 1 primordia and young fruiting bodies of three basidiomycete species

\begin{tabular}{|c|c|c|c|c|}
\hline Cluster & C. cinerea locus & S. commune locus & L. bicolor locus & Functional annotation* \\
\hline \multirow[t]{22}{*}{$1(\mathrm{PC}+\mathrm{0}: 95)$} & CC1G_01874 & SCHCODRAFT_73392 & LACBIDRAFT_301146 & Hypothetical protein \\
\hline & CC1G_02466 & SCHCODRAFT_109665 & LACBIDRAFT_297494 & Hypothetical protein \\
\hline & CC1G_00973 & SCHCODRAFT_83399 & LACBIDRAFT_293318 & Chitin deacetylase \\
\hline & CC1G_10475 & SCHCODRAFT_57566 & LACBIDRAFT_295571 & Aromatic peroxygenase precursor \\
\hline & CC1G_14095 & SCHCODRAFT_48101 & LACBIDRAFT_294461 & Hypothetical protein \\
\hline & CC1G_03094 & SCHCODRAFT_52606 & LACBIDRAFT_315775 & Hypothetical protein \\
\hline & CC1G_06074 & SCHCODRAFT_76530 & LACBIDRAFT_293318 & Carbohydrate esterase family 4 protein \\
\hline & CC1G_10044 & SCHCODRAFT_108884 & LACBIDRAFT_306386 & Related to S.pombe pac2 protein \\
\hline & CC1G_00753 & SCHCODRAFT_234371 & LACBIDRAFT_305130 & Hypothetical protein \\
\hline & CC1G_14786 & SCHCODRAFT_52306 & LACBIDRAFT_246776 & MFS nicotinic acid transporter Tna1 \\
\hline & CC1G_01301 & SCHCODRAFT_72462 & LACBIDRAFT_309640 & Hypothetical protein \\
\hline & CC1G_05059 & SCHCODRAFT_52448 & LACBIDRAFT_308735 & Symbiosis-related protein \\
\hline & CC1G_11437 & SCHCODRAFT_67374 & LACBIDRAFT_317173 & Putative aquaporin 6 \\
\hline & CC1G_08178 & SCHCODRAFT_237423 & LACBIDRAFT_323328 & Thioesterase family protein \\
\hline & CC1G_08180 & SCHCODRAFT_237423 & LACBIDRAFT_323328 & Thioesterase \\
\hline & CC1G_01879 & SCHCODRAFT_257636 & LACBIDRAFT_326397 & mei2 protein Piriformospora \\
\hline & CC1G_05223 & SCHCODRAFT_70203 & LACBIDRAFT_250946 & DUF1275 domain protein \\
\hline & CC1G_12219 & SCHCODRAFT_28806 & LACBIDRAFT_317102 & Related to velvet $A$ protein \\
\hline & CC1G_10750 & SCHCODRAFT_86141 & LACBIDRAFT_184665 & Glutathione S-transferase \\
\hline & CC1G_04060 & SCHCODRAFT_13677 & LACBIDRAFT_180892 & Hydrophobin-251 \\
\hline & CC1G_10471 & SCHCODRAFT_232646 & LACBIDRAFT_295571 & Aromatic peroxygenase precursor \\
\hline & CC1G_.12330 & SCHCODRAFT_16019 & LACBIDRAFT_256021 & S-layer domain-containing protein \\
\hline \multirow[t]{7}{*}{2 (PC: 0.99) } & CC1G_00069 & SCHCODRAFT_48115 & LACBIDRAFT_312065 & C factor cell-cell signaling protein \\
\hline & CC1G_00217 & SCHCODRAFT_46102 & LACBIDRAFT_323571 & Non-Catalytic module family EXPN protein \\
\hline & CC1G_03515 & SCHCODRAFT_82058 & LACBIDRAFT_328112 & Hydrophobin-like protein \\
\hline & CC1G_04659 & SCHCODRAFT_110821 & LACBIDRAFT_298314 & Hypothetical protein \\
\hline & CC1G_05652 & SCHCODRAFT_232455 & LACBIDRAFT_309898 & TKL/TKL-ccin protein kinase \\
\hline & CC1G_09209 & SCHCODRAFT_110821 & LACBIDRAFT_298284 & BTB/POZ domain containing protein \\
\hline & CC1G_10966 & SCHCODRAFT_258323 & LACBIDRAFT_236299 & rCop c3 \\
\hline \multirow[t]{6}{*}{3 (PC: 0.99) } & CC1G_02571 & SCHCODRAFT_76530 & LACBIDRAFT_293318 & Chitin deacetylase \\
\hline & CC1G_03037 & SCHCODRAFT_53388 & LACBIDRAFT_239714 & Monocarboxylate transporter \\
\hline & CC1G_03320 & SCHCODRAFT_39718 & LACBIDRAFT_145110 & Spo11 \\
\hline & CC1G_09616 & SCHCODRAFT_235946 & LACBIDRAFT_310809 & Prenyl cysteine carboxyl methyltransferase \\
\hline & CC1G_06563 & SCHCODRAFT_46720 & LACBIDRAFT_243581 & Exo-beta-1,3-glucanase \\
\hline & CC1G_12688 & SCHCODRAFT_55636 & LACBIDRAFT_296585 & Aldo/keto reductase \\
\hline \multirow[t]{2}{*}{4 (PC: 0.99) } & CC1G_03949 & SCHCODRAFT_258034 & LACBIDRAFT_298461 & Salicylate hydroxylase \\
\hline & CC1G_05817 & SCHCODRAFT_258034 & LACBIDRAFT_298461 & Salicylate 1-monooxygenase \\
\hline \multirow[t]{6}{*}{5 (PC: 0.99) } & CC1G_06868 & SCHCODRAFT_53362 & LACBIDRAFT_182606 & Endo-1,3(4)-beta-glucanase \\
\hline & CC1G_07550 & SCHCODRAFT_56140 & LACBIDRAFT_291657 & Lipase \\
\hline & CC1G_05781 & SCHCODRAFT_72461 & LACBIDRAFT_291413 & OrdA protein \\
\hline & CC1G_08860 & SCHCODRAFT_80181 & LACBIDRAFT_172283 & Cation/H + exchanger \\
\hline & CC1G_09431 & SCHCODRAFT_49922 & LACBIDRAFT_190903 & O-methylsterigmatocystin oxidoreductase \\
\hline & CC1G_11000 & SCHCODRAFT_107054 & LACBIDRAFT_310382 & Hypothetical protein \\
\hline
\end{tabular}


Table 5 Up- and down-regulation of orthologous loci is conserved in stage 1 primordia and young fruiting bodies of three basidiomycete species (Continued)

\begin{tabular}{|c|c|c|c|c|}
\hline \multirow[t]{23}{*}{6 (PC: 0.94) } & CC1G_02440 & SCHCODRAFT_103563 & LACBIDRAFT_308947 & ras GEF \\
\hline & CC1G_07544 & SCHCODRAFT_80832 & LACBIDRAFT_243185 & DUF89-containing protein \\
\hline & CC1G_05410 & SCHCODRAFT_104205 & LACBIDRAFT_301153 & Hypothetical protein \\
\hline & CC1G_02628 & SCHCODRAFT_82883 & LACBIDRAFT_327335 & $\mathrm{C} 2 \mathrm{~h} 2$ conidiation transcription factor FlbC \\
\hline & CC1G_11894 & SCHCODRAFT_68168 & LACBIDRAFT_296675 & bas1, putative \\
\hline & CC1G_05329 & SCHCODRAFT_85265 & LACBIDRAFT_300118 & Hypothetical protein \\
\hline & CC1G_09061 & SCHCODRAFT_27314 & LACBIDRAFT_308057 & MNNG and nitrosoguanidine resistance protein \\
\hline & CC1G_02380 & SCHCODRAFT_77933 & LACBIDRAFT_314347 & Clavaminate synthase-like protein \\
\hline & CC1G_05793 & SCHCODRAFT_85265 & LACBIDRAFT_300118 & Hypothetical protein \\
\hline & CC1G_14014 & SCHCODRAFT_49922 & LACBIDRAFT_248655 & O-methylsterigmatocystin oxidoreductase \\
\hline & CC1G_11136 & SCHCODRAFT_232299 & LACBIDRAFT_294457 & Hypothetical protein \\
\hline & CC1G_00780 & SCHCODRAFT_106836 & LACBIDRAFT_305061 & BGP, partial \\
\hline & CC1G_03120 & SCHCODRAFT_83385 & LACBIDRAFT_307143 & Endoglucanase II \\
\hline & CC1G_02257 & SCHCODRAFT_46132 & LACBIDRAFT_295167 & Metalloprotease \\
\hline & CC1G_04116 & SCHCODRAFT_75425 & LACBIDRAFT_179508 & Glutathione S-transferase Gst3 \\
\hline & CC1G_11081 & SCHCODRAFT_75425 & LACBIDRAFT_179508 & Glutathione S-transferase \\
\hline & CC1G_12752 & SCHCODRAFT_50449 & LACBIDRAFT_253329 & Cytochrome P450 \\
\hline & CC1G_12253 & SCHCODRAFT_269973 & LACBIDRAFT_296037 & Nrg1-like Zn-finger transcription factor \\
\hline & CC1G_11786 & SCHCODRAFT_58473 & LACBIDRAFT_315853 & Hypothetical protein \\
\hline & CC1G_09938 & SCHCODRAFT_80558 & LACBIDRAFT_330070 & Ferritin/ribonucleotide reductase-like-protein \\
\hline & CC1G_02724 & SCHCODRAFT_255861 & LACBIDRAFT_295183 & Hypothetical protein \\
\hline & CC1G_05802 & SCHCODRAFT_65657 & LACBIDRAFT_256254 & Indole-3-acetaldehyde dehydrogenase \\
\hline & CC1G_15739 & SCHCODRAFT_76887 & LACBIDRAFT_146952 & Ricin B fold protein \\
\hline
\end{tabular}

*Functional annotation as determined by PSI-BLAST.

†Pearson correlation coefficient.

as mei2 (CC1G_01879) and spo11 (CC1G_03320), are up-regulated during the early stages of fruiting body formation in basidiomycetes.

Given the up-regulation of a conserved Velvet-domain containing protein in primordia of the analyzed basidiomycetes, the conservation and expression pattern of Velvet-interacting proteins previously characterized in Aspergillus [42] was examined. With the exception of $\operatorname{cry} A$, orthologs to these Velvet-interacting proteins can be found in C. cinerea, L. bicolor and S. commune (Additional file 9). Contrary to the conserved transcriptional regulation observed for genes encoding Velvet domaincontaining proteins, little conservation in expression is evident for the orthologs to $\operatorname{ros} A / \operatorname{nos} A, s t u A, n s d D, p p o A$, laeA or fphA (Additional file 10: Figure S4). Nevertheless, conserved down-regulation during sexual development is shown for $v e l B$ and $k a p A$, suggesting that a fraction of the Velvet-associated regulon described for ascomycetes might be playing a role during sexual development in basidiomycetes (Additional file 10: Figure S4). Similarly, down-regulation of transcription factors such as $f l b C$ (a paralog to $\mathrm{C} 2 \mathrm{H} 2$ known to regulate development in $A$. nidulans [45]), nrg1 and bas1 during early mushroom formation was conserved between the three basidiomycetous species.

Transcription factor mutants (Bri1, Hom1, Gat1, Fst3, C2h2, Fst4 and Hom2) altering normal sexual development in S. commune have been described [46,47]. Although orthologs of these transcription factors are present in C. cinerea and L. bicolor, the respective genes do not show a conserved expression pattern, indicating that there might be differences in the interplay between these factors during fruiting body formation between different basidiomycetes (Additional file 11: Figure S5).

\section{Shotgun MS analysis of PBS-soluble VM and S1P proteins} In order to confirm protein expression of some of the genes found to be differentially expressed by RNA-seq, we assessed the PBS-soluble C. cinerea proteome in VM and S1P by LC-MS. The analysis detected peptides corresponding to a total of 493 proteins in the samples, including 41, 141 and 311 proteins in S1P, VM or both, respectively (Additional file 12: Table S6). This analysis is highly biased towards abundant and soluble proteins 
and is likely to have failed to detect peptides from most of the loci identified by RNA-seq. Nevertheless, this method allowed us to confirm the translation of 12 transcripts up-regulated in S1P and 50 transcripts upregulated in VM into proteins in the respective tissues (Additional file 13: Table S7).

\section{Discussion}

Our data shows a transcriptional switch during the differentiation of primordia in C. cinerea comprising $11 \%$ of the protein-encoding genome being up- or downregulated. Differential transcription analyses carried out in other basidiomycetous fungi, such as Agrocybe aegerita, Cordyceps militaris and Ganoderma lucidum, have revealed similar or even more extensive transcriptional switches [48-50]. Taking the differential expression threshold used in the present study (log2(fruiting body/ vegetative mycelium) $\geq 3$ ), $25 \%$ and $30 \%$ out of $18474 \mathrm{~A}$. aegerita loci are up-regulated in fruiting bodies and vegetative mycelium, respectively [48]. Similarly, C. militaris up-regulates $40 \%$ loci during fruiting body formation [49], while G. lucidum boosts the transcription of at least 27\% measured loci in its sexual organs [50].

The enrichment among the up-regulated loci in S1P of the functional annotation tag "N-methyltransferase" (histone-lysine $\mathrm{N}$-methyltransferase, 7 loci in total) suggests that epigenetic regulation of gene expression or chromosome dynamics may play an important role during sexual development in C. cinerea. In Saccharomyces cerevisiae, histone $\mathrm{H} 3$ lysine 4 trimethylation marks the sites where double-strand breaks, the first events during interhomolog recombination, occur [51]. Up-regulation of histone-lysine $\mathrm{N}$-methyltransferases in S1P is in accordance with karyogamy and early meiotic phases taking place at stage 1 primordia during fruiting body formation [6].

Several previously characterized nematotoxic and insecticidal proteins $[18,20]$ were found to be up-regulated in S1P. Among these proteins, lectins appear to be most abundant. The fruiting body-specific ricin B-like lectins CCL1 and CCL2 were previously shown to be toxic to C. elegans due to the binding to $\alpha 1,3$-fucosylated $\mathrm{N}$ glycan cores in the intestine of L1 worms [34]. In accordance to a previous study [52], we found that the tetrameric galectin CGL1 (CC1G_05003) was highly induced in $C$. cinerea fruiting bodies. Similar to CCL1 and CCL2, CGL1 and its isogalectin CGL2 (CC1G_05005) showed toxicity against $C$. elegans which was dependent on binding to a Gal $\beta 1,4 \mathrm{Fuc} \alpha 1,6$-epitope on $\mathrm{N}$-glycan cores present in the worm intestine [35]. Protease inhibition is another defense strategy against predation in $C$. cinerea fruiting bodies. We found the locus encoding the serine protease inhibitor Cospin1 (CC1G_09480) and its isoprotein Cospin2 (CC1G_09479) among the top 50 most highly transcribed and differentially expressed loci in S1P. Cospin1 was previously shown to be toxic against Drosophila melanogaster larvae indicative of its role in fruiting body defense against arthropod predation [20]. In this study, we demonstrate that CC1G_11805 is toxic for C. elegans and A. aegypti larvae, analogous to the toxicity of aerolysin/ETX pore-forming domaincontaining Bacillus sphaericus protein towards larvae of the mosquito Culex quinquefasciatus [53], suggesting that pore formation is another defense strategy of $C$. cinerea primordia against predators. The high absolute transcription of these defense loci in S1P can be explained by the extensive resource allocation to these organs and the significance of these organs for reproduction of the fungus. The expression of putative secreted and antibacterial proteins in C. cinerea vegetative mycelium, on the other hand, probably reflects the confrontation of this tissue with bacterial competitors although the antibacterial activity of these proteins has still to be demonstrated. In summary, the differential expression of defense proteins in the different tissues of $C$. cinerea is an adaptation of the fungus to the different environmental challenges with which these tissues are confronted.

Surprisingly, with the exception of $c f s 1$, none of the genes previously shown to play a role in $C$. cinerea fruiting body formation were differentially expressed in stage 1 primordia. Mutations in $r m t 1, u b c 2$ and $\operatorname{snf5}[14,15,17]$ block development before initials are formed ( $48 \mathrm{~h}$ before S1P develop). In contrast, $d s t 1, d s t 2$, eln 3 and exp 1 are involved in processes taking place in stage 2 primordia $(24 \mathrm{~h}$ after S1P), immature fruiting bodies (48-72 $\mathrm{h}$ after S1P) and decaying fruiting bodies (72 $\mathrm{h}$ after S1P) $[6,11,12,16]$. Thus, a possible explanation of our results is that these genes might be regulated before or after the formation of S1P takes place. Intriguingly, the mutation of $c f s 1$ blocks development right at the transition between initials and S1P. This observed up-regulation of $c f s 1$ in S1P supports a function for this cyclopropane fatty acid synthase in the development of S1P from initials.

The Velvet protein regulon, including genes $n s d D$, $\operatorname{ros} A$, veA and $s t u A$ among others, coordinates sexual development and secondary metabolism in filamentous ascomycetes [41,42]. Velvet domains structurally resemble the RHD-like fold present in the transcription factor $N F-\kappa \beta$ that plays a central role in animal immunity, suggesting a common evolutionary origin for these two protein families [54]. Overexpression of $v e A$ and $n s d D$ in $A$. nidulans induces the formation of nursing Hülle cells surrounding the cleistothecia [41]. Homologous genes in C. cinerea, CC1G_12219 and CC1G_06391, showed high expression in S1P suggesting a function of these loci in the gene circuitry involved in fruiting body development in this fungus. On the other hand, $\operatorname{ros} A$, an $A$. nidulans 
transcription factor inhibiting sexual development in low-carbon culture, is expressed in A. nidulans asexual hyphae where it represses the transcription of sexual development regulators such as $n s d D, v e A$ and $s t u A$ [55]. Similarly, rosA-homologous $C$. cinerea gene CC1G_ 07059, is expressed in vegetative mycelium where it might be inhibiting sexual development. Taken together, these results suggest a conserved role of the Velvet protein regulon during sexual development in the ascomycete $A$. nidulans and the basidiomycete $C$. cinerea.

Genes encoding Velvet domain-containing proteins were also found to be up-regulated in fruiting bodies of S. commune and L. bicolor [43,44]. However, (with the exception of $v e l B$ and $k a p A$ ) genes encoding Velvetassociated proteins such as RosA/NosA, StuA, NsdD, PpoA, LaeA, FphA or CryA [42], do not show interspecies conservation of differential expression. Similar lack of transcriptional conservation between the three analyzed basidiomycete species was observed for orthologs to transcription factors shown to be involved in $S$. commune sexual development $[46,47]$. Taken together, this evidence suggests that basidiomycetes show speciesspecific divergence of transcriptional regulation in orthologous genes similar to plants [56].

A broader comparison of the transcriptomes of the three analyzed basidiomycete species, comprising all the genes differentially expressed in $C$. cinerea during sexual development, revealed the presence of a conserved gene regulation circuitry among basidiomycetes during fruiting body formation. As previously observed in fruiting bodies of ascomycetes [57], our orthology analysis showed that a large fraction of genes differentially expressed in S1P corresponds to loci which are not present in the basidiomycetes $L$. bicolor and S. commune. These results are in agreement with previous observations in plants and animals that genes associated with sexual reproduction rapidly evolve [58,59]. The existence of clusters comprising conserved up- or down-regulated loci with little inter-species expression variability, suggests that regulation of these loci evolved under stabilizing selection [60]. Sequence and expression conservation might imply an essential role of these genes in fruiting body development and sexual reproduction in basidiomycetes. Interestingly, L. bicolor and C. cinerea orthologs to transcription factors described previously as important for sexual development in S. commune, such as Bri1, Hom1, Gat1, Fst3, C2h2, Fst4 or Hom2 [46,47], do not show conserved transcriptional conservation in basidiomycetes, suggesting that novel regulatory pathways related to sexual development did evolve once speciation occurred. As a proof of concept, Traeger and collaborators found that the fruiting body specific transcription factor pro44 (orthologous to the velvet regulonassociated transcription factor $n s d D$ ) in the ascomycetes
Sordaria macrospora and Pyronema confluens is a core regulator of perithecia maturation. S. macrospora deficient in pro44 was shown to be sterile and unable to produce mature perithecia [57]. In addition to a Velvet domaincontaining protein, the expression of the RNA binding protein mei2 (CC1G_01879), a master meiosis regulator in yeast and plants $[61,62]$ protecting meiosis-specific transcripts from degradation by the DSR-Mmi system, was increased in S1P or YFB of C. cinerea, S. commune and L. bicolor. Similarly, the transcriptional regulation of spo11, encoding a protein inducing meiotic recombination in S. cerevisiae and C. cinerea [63], was also conserved. This induction of meiosis regulators in multiple species reflects the role of mushrooms in the production and dispersal of basidiospores.

With regard to the comparative transcriptome analysis of the three basidiomycete species, it should be noted that in case of S. commune and L. bicolor, only data of monokaryotic vegetative mycelia was available $[43,44]$, whereas in case of $C$. cinerea, the transcriptome of an isogenic homodikaryotic mycelium was determined. Thus, the degree of conserved transcriptional regulation during sexual development between C. cinerea, L. bicolor and $S$. commune is potentially larger than observed.

Lastly, the proteome of an organism provides a more direct image of its phenotype than the transcriptome [64]. Detection of proteins using label-free shotgun mass spectrometry fails to detect low abundance proteins in complex total extracts and allows only semi-quantitative estimation of relative protein amounts. These properties are in contrast to the superior standardization and sensitivity achieved by state of the art nucleotide sequencing technologies. Nevertheless, LC-MS spectra showed the presence of peptides derived from the nematotoxic lectin CCL1 (CC1G_11778) and the nematotoxic/insecticidal aerolysin/ETX pore-forming domain-containing protein CC1G_11805 in the PBS-soluble protein extract of $C$. cinerea stage 1 primordia, indicating that these cytoplasmic toxins are indeed expressed at protein level in these organs.

The recent development of gene targeting tools in $C$. cinerea $[13,65]$, will help to test whether some of the genes identified as differentially regulated during sexual development in multiple basidiomycete species, play a role in this process.

\section{Conclusions}

In this work, we show that sexual reproduction in $C$. cinerea A43mutB43mut involves the differential transcription of at least $11 \%$ of its protein-coding genome. Differentially transcribed genes include several genes coding for defense proteins that protect fruiting structures and vegetative mycelia from predators and competitors, respectively. Moreover, our data infers a role of the 
Velvet protein family during fruiting body formation in basidiomycetes and thus, a conserved role of this protein family during sexual development in dikaryotic filamentous fungi. Finally, the result of the comparative transcriptome analysis of $C$. cinerea, $S$. commune and $L$. bicolor suggest that a conserved set of orthologous genes regulates sexual development in the phylum Basidiomycota. Additional experiments addressing the function of the differentially expressed gene products are required to confirm these hypotheses.

\section{Methods}

\section{Strains and culture conditions}

The dikaryotic, self-compatible $C$. cinerea strain A43mut B43mut (AB) [66] was grown on $30 \mathrm{~mL}$ YMG plates (0.4\% yeast extract, $1 \%$ malt extract, $50 \mathrm{mM}$ glucose and $1.5 \%$ agar) at $37^{\circ} \mathrm{C}$ in the dark for $96 \mathrm{~h}$ and transferred to $25^{\circ} \mathrm{C}, 90 \%$ humidity and $12 \mathrm{~h}$ photoperiod for fruiting body production. 1 to $2 \mathrm{~mm} \mathrm{AB} \mathrm{S1P} \mathrm{[6]} \mathrm{were} \mathrm{harvested}$ after $72 \mathrm{~h}$, flash-frozen in liquid nitrogen and stored at $-80^{\circ} \mathrm{C}$ for later use. C. cinerea AB VM was grown in duplicate on YMG plates covered with cellophane discs for $96 \mathrm{~h}$ at $37^{\circ} \mathrm{C}$ in the dark and harvested independently before being flash frozen and stored at $-80^{\circ} \mathrm{C}$.

\section{Total RNA extraction}

Primordia and mycelia were lyophilized and S1Ps were separated in two pools of $20 \mathrm{mg}$ each. From each VM replicate or S1P pool, $20 \mathrm{mg}$ dry material were lysed in three FastPrep FP120 homogenization steps of $45 \mathrm{~s}$ at $4.5,5.5$ and $6.5 \mathrm{~m} / \mathrm{s}$ in the presence of $250 \mathrm{mg} 0.5 \mathrm{~mm}$ glass beads, cooling the samples for $5 \mathrm{~min}$ on ice between steps. RNA was extracted using $1 \mathrm{~mL}$ Qiazol (Qiagen) and $0.2 \mathrm{~mL}$ chloroform ReagentPlus (SigmaAldrich). The solution was centrifuged at $12000 \times \mathrm{g}$ for $15 \mathrm{~min}$ at $4^{\circ} \mathrm{C}$; thereafter, RNA from the resultant aqueous phase was washed on-column using the RNeasy Lipid Tissue Mini Kit (Qiagen) and eluted in $60 \mu \mathrm{L}$ RNase-free water. Concentration and integrity of the purified RNA were determined with a Qubit (1.0) fluorometer (Life Technologies) and a Bioanalyzer 2100 (Agilent), respectively. Samples with a 260/280 nm ratio of $1.8-2.1$ and a $28 \mathrm{~S} / 18 \mathrm{~S}$ ratio of $1.5-2$ were later used in library construction.

\section{SOLiD 4 library construction}

Whole transcriptome libraries from two S1P pools and two VM replicates were produced using MicroPolyA Purist Kit (Ambion) and SOLiD Total RNA-Seq kit (Applied Biosystems). Briefly, approximately $200 \mathrm{ng} / \mathrm{sample}$ poly (A)-positive RNA was enriched using MicroPoly (A) Purist Kit from 15-20 $\mu \mathrm{g}$ total RNA. Quality and concentration of the extracted poly (A)-positive RNA was re-assessed as described above, and poly (A)-positive
RNA was digested with RNase III. Ligation of the adaptor mix and reverse transcription was performed following the manufacturer instructions. cDNA libraries were size selected for 150-250 bp fragments, amplified in 15-18 PCR cycles using barcoded adaptor primers and purified with PureLink PCR micro kit (Invitrogen). These barcoded cDNA libraries were then amplified by emulsion PCR from 0.5 pM template. Sequencing beads from the barcoded libraries were pooled and loaded on a SOLiD 4 slide (Applied Biosystems), according to manufacturer's instructions. SOLiD ToP Sequencing chemistry was used to produce pair end (50 bp $+35 \mathrm{bp}$ ) sequencing reads.

\section{qRT-PCR validation}

RNA-seq results were validated by qRT-PCR. Singlestranded cDNA from one biological replicate per sample was synthesized using Transcriptor Universal cDNA Master (Roche) from $2 \mu \mathrm{g}$ total RNA. $20 \mu \mathrm{L}$ qRT-PCR reactions were mixed in three technical replicates per primer set and sample, containing $900 \mathrm{nM}$ forward and reverse primers designed to span exon-exon junctions (Additional file 14: Table S8), $10 \mu \mathrm{L} 2 \times$ FastStart Universal SYBR Green Master (Rox, Roche) and $1 \mathrm{ng} / \mu \mathrm{L}$ cDNA template. qRT-PCR was performed in a Rotor-Gene 3000 (Corbett Life Science) with the following thermal profile: a hold step at $95^{\circ} \mathrm{C}$ for $15 \mathrm{~min}$ followed by $40 \mathrm{cy}$ cles of $95^{\circ} \mathrm{C}$ for $15 \mathrm{~s}, 58^{\circ} \mathrm{C}$ for $30 \mathrm{~s}$ and $72^{\circ} \mathrm{C}$ for $30 \mathrm{~s}$. In order to control the specificity of amplification, the reaction was concluded with a melting curve analysis ramping from $55^{\circ} \mathrm{C}$ to $99^{\circ} \mathrm{C}$ in steps of $1^{\circ} \mathrm{C}$ every $5 \mathrm{~s}$. PCR efficiencies and cycle thresholds were obtained using LinRegPCR 12 [67] and differential expression ratios were calculated by the $C_{T}$ difference formula [68]. Tubulin beta chain (CC1G_04743) was used as a house keeping normalizer. In addition, water or $1 \mathrm{ng} / \mu \mathrm{L}$ RNA were included as negative control reactions. To further validate the significance of the RNA-seq-derived differential expression analysis, the constitutive expression of an array of housekeeping loci commonly used in qRT-PCR normalization [69-75] was verified in the sequencing datasets after library size normalization.

\section{Bioinformatic analysis}

Fastqc files were used to filter and trim the reads to be mapped. Strand-specific reads were mapped to the third annotation (September 2010) of the C. cinerea okayama7\#130 genome hosted at the Broad Institute $(C$. cinerea Sequencing Project, Broad Institute of Harvard and MIT (http://www.broadinstitute.org/)). SOLiD mapped reads were counted using Cufflinks [76]. All the sequences were deposited in the ArrayExpress database (http://www. ebi.ac.uk/arrayexpress/) under the accession number [EMTAB-1968]. To determine the percentage of loci 
showing baseline expression, 5 reads/locus were taken as a minimal threshold [77]. Library size normalization (scaling method), fold change calculation per locus and fisher exact test comparing mycelia and primordia libraries were performed using the edgeR package [78] using sense-read counts. Fisher exact test p-value $\leq 0.05$ and fold change $\geq 8$ were the criteria established to classify a locus as differentially expressed in one of the two compared samples. Functional annotation of loci found to be developmentally regulated was explored by PSI-BLAST [79]. Enrichment of annotation terms in differentially expressed loci was visualized in tag clouds constructed by Wordle (c) IBM Corporation) [32]; common tags such as "protein", "hypothetical", "domain", "containing", "family", "putative", "similar", "probable", "related" and "subunit" were excluded. A complementary functional annotation clustering was performed with the Database for Annotation, Visualization and Integrated Discovery (DAVID) 6.7 [33] using default annotation categories and the C. cinerea okayama7\#130 translated genome as background. SignalP 4.1 [80] and TMHMM v. 2.0 [81] were used to predict the presence of secretion signal and transmembrane helices in developmentally regulated loci. Presence of nuclear localization signals (NLSs) in members of the Velvet protein family was assessed with NLStradamus [82]. To analyze the similarity in the gene expression programs associated to early stages in fruiting body development across different basidiomycetous fungi, orthologous genes to differentially expressed loci in C. cinerea S1P were identified by PSI-BLAST (best hit showing an E-value $\leq 0.005$ ) in the genomes of Schizophyllum commune 4-39/4-40 and Laccaria bicolor S238N-H82. Expression data were retrieved from the original studies where the gene expression of vegetative mycelium and S1P or YFB from $S$. commune [43] and L. bicolor [44], respectively, was measured. First, $\log 2$ expression ratios were calculated for stage 1 primordia against monokaryon mycelium from $S$. commune using tags per million per locus. Similarly, log2 ratios were calculated for "young fruiting bodies" compared to "free living mycelium" (the latter corresponding to the average of two replicates) of $L$. bicolor from quantile-normalized Robust multichip average values. A centroid-linkage hierarchical clustering analysis of the computed $\log 2$ ratios was performed with Cluster 3.0 and heat maps were generated and visualized using TreeView 3 [83].

A more detailed orthology and expression analysis was carried out for loci known to encode proteins interacting with Velvet domain-containing proteins involved in sexual development and secondary metabolite production in Aspergillus [42]. The sequences of RosA, NosA, StuA, NsdD, PpoA, VelB, LaeA, KapA FphA and CryA from $A$. nidulans were used to retrieve the corresponding orthologs from the protein-coding genomes of $C$. cinerea
Okayama 7, S. commune 4-39/4-40 and L. bicolor S238N-H82. Orthologs were defined as the best hits in a PSI-BLAST showing E-values $\leq 0.005$. Progressive multiple sequence alignments for the orthologs present in $A$. clavatus, A. fumigatus, $A$. oryzae and $A$. nidulans, as well as in the three basidiomycetous species considered, were constructed in CLUSTAL W [84]. Finally, Velvet domain-containing proteins in C. cinerea, S. commune and $L$. bicolor were identified in Pfam and SMART diagrams were created [85].

\section{LC-MS/MS based shotgun proteomics}

Twenty mg lyophilized VM from a single plate or a S1P pool were lysed in a FastPrep FP120 during $40 \mathrm{~s}$ at $6 \mathrm{~m} / \mathrm{s}$ using $200 \mathrm{mg} 0.5 \mathrm{~mm}$ glass beads and $600 \mu \mathrm{L}$ PBS supplemented with $1 \mathrm{mM}$ phenylmethanesulfonylfluoride (PMSF) and $1 \times$ Complete Protease Inhibitor Cocktail (Roche). The lysates were centrifuged for $15 \mathrm{~min}$ at 16000 $\mathrm{xg}$ and $4^{\circ} \mathrm{C}$, and the supernatants (soluble protein extracts) recovered. Soluble protein extracts from VM and S1P were further processed by filter-aided sample preparation (FASP) method as previously described [86]. In brief, protein extracts were loaded onto an Amicon column equipped with a $10 \mathrm{kDa}$ MWCO membrane (Millipore), reduced with $55 \mathrm{mM}$ dithiothreitol at $37^{\circ} \mathrm{C}$ for $1 \mathrm{~h}$ and alkylated with $65 \mathrm{mM}$ iodoacetamide in the dark at $37^{\circ} \mathrm{C}$ for $1 \mathrm{~h}$. Reduced and alkylated extracts were digested with sequencing grade porcine trypsin (Roche) for $18 \mathrm{~h}$ at $37^{\circ} \mathrm{C}$ in $25 \mathrm{mM}$ ammonium bicarbonate, $\mathrm{pH}$ 8.5. Digested peptide mixtures were collected by centrifugation and dried in a Savant SpeedVac (Thermo Scientific). All samples were de-salted by $\mathrm{C} 18$ ZipTip before mass spectrometry analysis.

Samples were analyzed on a LTQ-Orbitrap Velos mass spectrometer (Thermo Fischer Scientific) coupled to an Eksigent-Nano-HPLC system (Eksigent Technologies). Peptides were suspended in $2.5 \%$ acetonitrile and $0.1 \%$ formic acid, loaded on a self-made tip column $(75 \mu \mathrm{m} \times$ $80 \mathrm{~mm}$ ) packed with reverse phase C18 material (AQ, $3 \mu \mathrm{m} 200 \AA$, Bischoff $\mathrm{GmbH}$ ) and eluted with $250 \mathrm{~nL} /$ min flow rate in a gradient from $3 \%$ to $50 \%$ of $B$ in $90 \mathrm{~min}, 97 \% \mathrm{~B}$ in $10 \mathrm{~min}$. One scan cycle comprised a full scan MS survey spectrum, followed by up to 20 sequential CID MS/MS on the most intense signals above a threshold of 1500 . Full-scan MS spectra (300-2000 m/z) were acquired in the FT-Orbitrap at a resolution of 60000 at $400 \mathrm{~m} / \mathrm{z}$, while CID MS/MS spectra were recorded in the linear ion trap. CID was performed with a target value of $1 \mathrm{E} 4$ in the linear trap, collision energy at $35 \mathrm{~V}, \mathrm{Q}$ value at 0.25 and activation time at $30 \mathrm{~ms}$. AGC target values were 5E5 for full FTMS scans and 1E4 for ion trap MSn scans. For all experiments, dynamic exclusion was used with one repeat count, $15 \mathrm{~s}$ repeat duration, and $60 \mathrm{~s}$ exclusion duration. For quantitation, each sample was measured in technical triplicates using the same parameters. 
All MS data from VM and S1P were converted to a peak list and searched against the C. cinerea okayama7\#130 proteome (predicted transcript translation) hosted at the Broad Institute $(C$. cinerea Sequencing Project, Broad Institute of Harvard and MIT (http:// www.broadinstitute.org/)) using the Mascot search engine (version 2.3) considering variable modifications: carbamidomethylation on cysteine and oxidation on methionine. The tolerance of mass accuracy of MS and MS/MS was $8 \mathrm{ppm}$ and $0.6 \mathrm{Da}$. The false discovery rate of proteome dataset was $1 \%$ and the score of each protein exceeded 30.

\section{Cloning and recombinant expression of CC1G_11805- encoding CDNA}

cDNA encoding CC1G_11805 was amplified from $C$. cinerea S1P-derived cDNA using the forward and reverse primers 5'-CCAGCTTAAAGGAGTCACAAGG-3' and 5' -AACGTTCAACGCCCAGCCAC-3', respectively, with a Pfu DNA polymerase. 3' adenines were added to the PCR fragment before ligation to the DNA amplification vector pGEM-T Easy (Promega). This pGEM-CC1G_ 11805 construct was used as a template to add NdeI and BamHI restriction sites using the primers $5^{\prime}$-GGGGG GCATATGTCTCAAGCAGGGATCACAC-3' and 5' -GG GGGGGGATCCTCAGATACGCCCGATGACTTC-3', respectively. The resulting product was digested with NdeI and BamHI in $2 \times$ Tango buffer (Thermo Scientific), ligated to a pre-digested pET24 expression vector (EMD Millipore), and used to transform chemocompetent $E$. coli BL21. Transformed colonies were selected on LB plates containing $50 \mu \mathrm{g} / \mathrm{mL}$ Kanamycin. CC1G_11805 recombinant expression and solubility were assessed as follows: pET24-CC1G_11805-containing E.coli BL21 was grown in LB broth supplemented with $50 \mu \mathrm{g} / \mathrm{mL}$ Kanamycin up to $\mathrm{OD}_{600}$ : 0.5 ; thereafter, the cultures were divided in two separated flasks and protein expression was induced for $18 \mathrm{~h}$ at $24^{\circ} \mathrm{C}$ by adding $1 \mathrm{mM}$ Isopropyl $\beta$-D-1-thiogalactopyranoside (IPTG, final concentration) to only one of the two subcultures. Cells were harvested, suspended in $1 \mathrm{~mL}$ PBS containing with $1 \mathrm{mM}$ phenylmethanesulfonylfluoride (PMSF) and lysed in a single FastPrep FP120 homogenization step of $35 \mathrm{~s}$ at $6 \mathrm{~m} / \mathrm{s}$ in the presence of $1 \mathrm{~g} 0.1 \mathrm{~mm}$ glass beads. The whole cell protein extract (WCE) was centrifuged for $5 \mathrm{~min}$ at $5000 \mathrm{xg}$ and $4^{\circ} \mathrm{C}$ (low speed centrifugation, LS) to remove cell debris and the supernatant transferred to a fresh tube to be centrifuged again for $30 \mathrm{~min}$ at $14000 \mathrm{xg}$ and $4^{\circ} \mathrm{C}$ (high speed centrifugation, HS). Samples were collected from the whole cell extracts (WCE and WCE + IPTG) and the two centrifugation supernatants (LS and HS), mixed with Laemmli buffer and denatured at $95^{\circ} \mathrm{C}$ for $5 \mathrm{~min}$ to be loaded on a $12 \%$ SDS-PAGE.

\section{Caenorhabditis elegans toxicity assay}

In order to evaluate the developmental toxicity of CC1G_11805 to nematodes, a C. elegans toxicity assay was performed as previously described [40]. In brief, $C$. elegans N2 and C. elegans pmk-1 (km25) (kindly provided by $\mathrm{M}$. O. Hengartner) were grown on NGM plates (50 mM NaCl, $2.5 \mathrm{~g} / \mathrm{L}$ bacteriological peptone, $13 \mathrm{mM}$ cholesterol and $1.7 \%$ agar) pre-seeded with E. coli OP50. Eggs were obtained by bleaching gravid hermaphrodites in $15 \mathrm{~mL}$ conical bottom tubes using a solution containing $0.5 \mathrm{~N} \mathrm{NaOH}$ and $1 \% \mathrm{NaClO}$ for $10 \mathrm{~min}$ and washing twice in $10 \mathrm{~mL}$ distilled deionized water $\left(\mathrm{ddH}_{2} \mathrm{O}\right)$. Clean eggs were transferred to a $1.5 \%$ agar plate and hatched for $18 \mathrm{~h}$ at $20^{\circ} \mathrm{C}$. L1 larvae were collected in PBS, counted and adjusted to 1.5 larvae $/ \mu \mathrm{L}$. Approximately 30 L1 larvae/replicate (4 replicates/treatment) were mixed in $200 \mu \mathrm{L}$ PBS with $\mathrm{OD}_{600}: 2$ IPTG-pre-induced E. coli BL21 expressing CC1G_11805 in flat bottom 96 well-plates. As a negative control, IPTG-pre-induced $E$. coli BL21 cells transformed with empty vector pET24 were used. Worms were incubated for $48 \mathrm{~h}$ at $20^{\circ} \mathrm{C}$ and the number of individuals reaching each developmental stage or dying was counted. A Mann Whitney test between the empty vector pET24 control and CC1G_ 11805 was run to test the statistical significance of the results observed.

\section{Aedes aegypti toxicity assay}

CC1G_11805 toxicity towards A. aegypti Rockefeller (kindly provided by W. Rudin and P. Müller) was tested as previously described [40]. In brief, 600-800 eggs were hatched in a glass petri dish containing $200 \mathrm{~mL}$ deionized water and $30 \mathrm{mg}$ ground fish food for $20 \mathrm{~h}$ at $28^{\circ} \mathrm{C}$ in the dark. Larvae were transferred to fresh $800 \mathrm{~mL}$ deionized water supplemented with $50 \mathrm{mg}$ ground fish food and incubated for $10 \mathrm{~h}$ at $28^{\circ} \mathrm{C}$ in order to obtain synchronized L2 larvae. Ten L2 larvae/replicate (4 replicates/treatment) were starved in $100 \mathrm{~mL}$ fresh deionized water in $100 \mathrm{~mL}$ Schott flasks for $6 \mathrm{~h}$ at $28^{\circ} \mathrm{C}$ before adding $1 \mathrm{~mL} \mathrm{OD}_{600}$ : 20 (Final $\mathrm{OD}_{600}: 0.2$ ) IPTG-preinduced $E$. coli BL21 (empty vector pET24, pET24CGL2 [18] or pET24-CC1G_11805). Larvae were incubated for $96 \mathrm{~h}$ at $28^{\circ} \mathrm{C}$ in the dark and the surviving individuals were counted. Percentages of surviving larvae/treatment were calculated. A Dunn's multiple comparison test between the empty vector pET24 control and the different treatments was run to test the statistical significance of the results observed.

\section{Availability of supporting data}

The data sets supporting the results of this article are available in the ArrayExpress repository under the accession number E-MTAB-1968 (http://www.ebi.ac.uk/ arrayexpress/). 


\section{Additional files}

Additional file 1: Table S1. Genome-wide differential expression analysis of C. cinerea S1P and VM.

Additional file 2: Table S2. Genes up-regulated in S1P and VM Additional file 3: Figure S1. RNA-seq data validation by qRT-PCR. The expression of four selected genes was validated by qRT-PCR. A comparable relative expression pattern was found for all the genes evaluated in S1P and VM with both techniques. RNA-seq data corresponds to the mean $\log 2($ S1PNM) of two biological replicates. qRT-PCR data show the mean $\log 2($ S1PNM) of three technical replicates from a single biological replicate of S1P and VM. Bars correspond to standard deviations. Dashed lines indicate the differential gene expression thresholds selected for this study $(\log 2($ S1PNM) $=+/-3)$.

Additional file 4: Table S3. RNA-seq expression of reference housekeeping loci.

Additional file 5: Table S4. DAVID functional annotation enrichment of genes up-regulated in S1P and VM.

Additional file 6: Figure S2. Scheme of fruiting body development in C. cinerea. Gene mutations preventing fruiting body development at different stages in C. cinerea are shown in blue. White and black sections indicate light and dark periods, respectively, corresponding to $12 \mathrm{~h}$ each. Numbers indicate the measured fold (S1PNM). A mutation in the S1P-specific locus CfS 1 stops sexual development at the initials stage. Figure adapted from Kües U, 2000

Additional file 7: Figure S3. Differential transcription comparison between genes coding for Velvet domain-containing proteins from three different basidiomycetes. Amino acid sequences corresponding to the full set of Velvet domain-containing proteins encoded in the genomes of $C$ cinerea, L. bicolor and S. commune were retrieved from Pfam (PF11754). SMART domain architecture diagrams are shown in (A). (B) Loci expression in S1P (C. cinerea and S. commune) or YFB (L. bicolor) relative to VM for all the velvet domain-containing proteins in the three basidiomycetes compared. N/E: No expression detected.

Additional file 8: Table S5. Orthology and expression of C. cinerea, S. commune y L. bicolor genes.

Additional file 9: Multiple sequence alignment between Velvetinteracting proteins of $C$. cinerea, $L$. bicolor, S. commune, $A$. clavatus, A. fumigatus, $A$. oryzae, $A$. niger and $A$. nidulans.

Additional file 10: Figure S4. Differential transcription comparison between genes coding for Velvet-associated proteins from three different basidiomycetes. C. cinerea, L. bicolor and S. commune loci homologous to those encoding VelvetA-associated proteins in the ascomycete Aspergillus clavatus (shown on top) were identified by PSI-BLAST (Best hit showing an E-value $<0.005$ ). Differential expression in S1P or YFB relative to VM is shown for the orthologs identified. $\log 2(\mathrm{~S} 1 \mathrm{P}$ or $\mathrm{YFB} / \mathrm{NM})>0$ indicates increased expression in S1P (C. cinerea or S. commune) or YFB (L. bicolor). On the contrary, a log2(S1P or YFB/VM) $<0$ represents a decreased expression in S1P or YFB. Blue and white locus IDs differentiate neighboring groups of orthologs in the chart. Expression of velB and $k a p A$ is conserved during sexual development among basidiomycetes. N/E: No expression detected.

Additional file 11: Figure S5. Differential transcription comparison between genes coding for transcription factors involved in sexual development in S. commune from three different basidiomycetes. Orthologs of transcription factors involved in sexual development in S. commune were identified by PSI-BLAST in the genomes of C. cinerea and L. bicolor. $\log 2((\mathrm{~S} 1 \mathrm{P}$ or YFB)NM) < 0: Down-regulation in S1P or YFB; $\log 2((S 1 P$ or YFB) NM) > 0: up-regulation in S1P or YFB. Domain architecture for each ortholog in the three species compared is shown in the right hand panel.

Additional file 12: Table S6. LC-MS analysis of C. cinerea S1P and VM. Additional file 13: Table S7. Genes up-regulated in S1P and VM detected by LC-MS.

Additional file 14: Table S8. $q R T-P C R$ validation primers.

\section{Competing interests}

The authors declare that they have no competing interests.

\section{Authors' contributions}

DFP prepared samples for RNA-seq and LC-MS, performed the differential expression and comparative transcriptome analyses and wrote the manuscript. CL carried out the LC-MS analysis of the PBS-soluble proteins from S1P and VM. NSJVDV cloned CC1G_11805, recombinantly expressed it in E. coli, and performed the toxicity assays on C. elegans and A. aegypti. MA and MK were involved in the experiment design and conception as well as in the data analysis and critical revision of the manuscript. All authors read and approved the final version of the manuscript.

\section{Acknowledgments}

We thank W. Rudin and P. Müller (Swiss Tropical and Public Health Institute, Basel, Switzerland) and M. O. Hengartner (Institute of Molecular Life Sciences, University of Zürich, Switzerland) for supplying A. aegypti eggs and C. elegans worms, respectively. We are grateful to scientific staff of the Functional Genomics Center Zurich, in particular to Andrea Patrignani for the library construction and Michal Okoniewski for his support in the mapping and counting of the sequenced reads. This project was supported by the Swiss National Science Foundation Grant 31003A_130671 and ETH Zürich Grant ETH-34 11-2.

Received: 13 February 2014 Accepted: 12 June 2014 Published: 19 June 2014

\section{References}

1. Dacks J, Roger AJ: The first sexual lineage and the relevance of facultative sex. J Mol Evol 1999, 48(6):779-783.

2. Heitman J, Sun S, James TY: Evolution of fungal sexual reproduction. Mycologia 2013, 105(1):1-27.

3. Crow JF: Advantages of sexual reproduction. Dev Genet 1994, 15(3):205-213

4. Doll K, Chatterjee S, Scheu S, Karlovsky P, Rohlfs M: Fungal metabolic plasticity and sexual development mediate induced resistance to arthropod fungivory. Proc Biol Sci 2013, 280(1771):20131219.

5. Kues U, Liu Y: Fruiting body production in Basidiomycetes. App/ Microbiol Biotechnol 2000, 54(2):141-152.

6. Kues U: Life history and developmental processes in the basidiomycete Coprinus cinereus. Microbiol Mol Biol Rev 2000, 64(2):316-353.

7. Moore D: Coprinopsis: an autobiography. 1st edition. Leipzig, Germany: CreateSpace Independent Publishing Platform; 2013.

8. Costa MC, Arroyo LG, Allen-Vercoe E, Stampfli HR, Kim PT, Sturgeon A, Weese JS: Comparison of the fecal microbiota of healthy horses and horses with colitis by high throughput sequencing of the V3-V5 region of the 16S rRNA gene. PLoS One 2012, 7(7):e41484.

9. Stajich JE, Wilke SK, Ahrén D, Au CH, Birren BW, Borodovsky M, Burns C, Canbäck B, Casselton LA, Cheng CK, Deng J, Dietrich FS, Fargo DC, Farman ML, Gathman AC, Goldberg J, Guigó R, Hoegger PJ, Hooker JB, Huggins A, James TY, Kamada T, Kilaru S, Kodira C, Kües U, Kupfer D, Kwan HS, Lomsadze A, Li W, Lilly WW, et al: Insights into evolution of multicellular fungi from the assembled chromosomes of the mushroom Coprinopsis cinerea (Coprinus cinereus). Proc Natl Acad Sci U S A 2010, 107(26):11889-11894.

10. Liu $Y$, Srivilai $P$, Loos $S$, Aebi M, Kues U: An essential gene for fruiting body initiation in the basidiomycete Coprinopsis cinerea is homologous to bacterial cyclopropane fatty acid synthase genes. Genetics 2006 , 172(2):873-884

11. Arima T, Yamamoto M, Hirata A, Kawano S, Kamada T: The eln3 gene involved in fruiting body morphogenesis of Coprinus cinereus encodes a putative membrane protein with a general glycosyltransferase domain. Fungal Genet Biol 2004, 41(8):805-812.

12. Muraguchi H, Fujita T, Kishibe Y, Konno K, Ueda N, Nakahori K, Yanagi SO, Kamada T: The exp1 gene essential for pileus expansion and autolysis of the inky cap mushroom Coprinopsis cinerea (Coprinus cinereus) encodes an HMG protein. Fungal Genet Biol 2008, 45(6):890-896.

13. Nakazawa T, Ando Y, Kitaaki K, Nakahori K, Kamada T: Efficient gene targeting in DeltaCc.ku70 or DeltaCc.lig4 mutants of the agaricomycete Coprinopsis cinerea. Fungal Genet Biol 2011, 48(10):939-946. 
14. Nakazawa $\mathrm{T}$, Kondo $\mathrm{H}$, Nakahori $\mathrm{K}$, Kamada T: A mutation in the Cc.ubc2 gene affects clamp cell morphogenesis as well as nuclear migration for dikaryosis in Coprinopsis cinerea. Fungal Genet Biol 2011, 48(5):519-525.

15. Nakazawa T, Tatsuta Y, Fujita T, Nakahori K, Kamada T: Mutations in the Cc rmt1 gene encoding a putative protein arginine methyltransferase alter developmental programs in the basidiomycete Coprinopsis cinerea. Curr Genet 2010, 56(4):361-367.

16. Kamada T, Sano H, Nakazawa T, Nakahori K: Regulation of fruiting body photomorphogenesis in Coprinopsis cinerea. Fungal Genet Biol 2010, 47(11):917-921.

17. Ando Y, Nakazawa T, Oka K, Nakahori K, Kamada T: Cc.snf5, a gene encoding a putative component of the SWI/SNF chromatin remodeling complex, is essential for sexual development in the agaricomycete Coprinopsis cinerea. Fungal Genet Biol 2013, 50:82-89.

18. Bleuler-Martínez S, Butschi A, Garbani M, Wälti MA, Wohlschlager T, Potthoff E, Sabotic J, Pohleven J, Lüthy P, Hengartner MO, Aebi M, Künzler M: A lectin-mediated resistance of higher fungi against predators and parasites. Mol Ecol 2011, 20(14):3056-3070.

19. Bleuler-Martinez S, Schmieder S, Aebi M, Kunzler M: Biotin-binding proteins in the defense of mushrooms against predators and parasites. Appl Environ Microbiol 2012, 78(23):8485-8487.

20. Sabotic J, Bleuler-Martinez S, Renko M, Avanzo Caglic P, Kallert S, Strukelj B, Turk D, Aebi M, Kos J, Kunzler M: Structural basis of trypsin inhibition and entomotoxicity of cospin, serine protease inhibitor involved in defense of Coprinopsis cinerea fruiting bodies. J Biol Chem 2012, 287(6):3898-3907.

21. Olombrada M, Martinez-Del-Pozo A, Medina P, Budia F, Gavilanes JG, GarciaOrtega L: Fungal ribotoxins: natural protein-based weapons against insects. Toxicon 2014, 83C:69-74

22. Luo H, Hallen-Adams HE, Scott-Craig JS, Walton JD: Ribosomal biosynthesis of alpha-amanitin in Galerina marginata. Fungal Genet Biol 2012, 49(2):123-129

23. Spiteller P: Chemical defence strategies of higher fungi. Chemistry 2008, 14(30):9100-9110.

24. Anke $\mathrm{H}$ : Insecticidal and Nematicidal Metabolites from Fungi. In The Mycota: A Comprehensive Treatise on Fungi as Experimental Systems for Basic and Applied Research/Industrial Applications. 2nd edition. Edited by Esser K. Heidelberg: Springer; 2010:123-163.

25. Rohlfs $M$, Churchill AC: Fungal secondary metabolites as modulators of interactions with insects and other arthropods. Fungal Genet Biol 2011, 48(1):23-34

26. Kaya E, Karahan S, Bayram R, Yaykasli KO, Colakoglu S, Saritas A: Amatoxin and phallotoxin concentration in Amanita phalloides spores and tissues. Toxicol Ind Health 2013, Epub ahead of print.

27. Cooper DN, Boulianne RP, Charlton S, Farrell EM, Sucher A, Lu BC: Fungal galectins, sequence and specificity of two isolectins from Coprinus cinereus. J Biol Chem 1997, 272(3):1514-1521.

28. Erjavec J, Kos J, Ravnikar M, Dreo T, Sabotic J: Proteins of higher fungi-from forest to application. Trends Biotechnol 2012, 30(5):259-273.

29. Wohlschlager T, Butschi A, Zurfluh K, Vonesch SC, auf dem Keller U, Gehrig P, Bleuler-Martinez S, Hengartner MO, Aebi M, Kunzler M: Nematotoxicity of Marasmius oreades agglutinin (MOA) depends on glycolipid binding and cysteine protease activity. J Biol Chem 2011, 286(35):30337-30343.

30. Boer W, Folman LB, Summerbell RC, Boddy L: Living in a fungal world: impact of fungi on soil bacterial niche development. FEMS Microbiol Rev 2005, 29(4):795-811.

31. Mygind PH, Fischer RL, Schnorr KM, Hansen MT, Sönksen CP, Ludvigsen S, Raventós D, Buskov S, Christensen B, De Maria L, Taboureau O, Yaver D, Elvig-Jørgensen SG, Sørensen MV, Christensen BE, Kjaerulff S, Frimodt-Moller $\mathrm{N}$, Lehrer Rl, Zasloff M, Kristensen $\mathrm{HH}$ : Plectasin is a peptide antibiotic with therapeutic potential from a saprophytic fungus. Nature 2005 437(7061):975-980.

32. Viegas FB, Wattenberg M, Feinberg J: Participatory visualization with Wordle. IEEE Trans Vis Comput Graph 2009, 15(6):1137-1144.

33. da Huang W, Sherman BT, Lempicki RA: Systematic and integrative analysis of large gene lists using DAVID bioinformatics resources. Nat Protoc 2009, 4(1):44-57.

34. Schubert M, Bleuler-Martinez S, Butschi A, Wälti MA, Egloff P, Stutz K, Yan S, Collot M, Mallet JM, Wilson IB, Hengartner MO, Aebi M, Allain FH, Künzler M: Plasticity of the beta-trefoil protein fold in the recognition and control of invertebrate predators and parasites by a fungal defence system. PLOS Pathog 2012, 8(5):e1002706.
35. Butschi A, Titz A, Wälti MA, Olieric V, Paschinger K, Nöbauer K, Guo X, Seeberger PH, Wilson IB, Aebi M, Hengartner MO, Künzler M: Caenorhabditis elegans $\mathrm{N}$-glycan core beta-galactoside confers sensitivity towards nematotoxic fungal galectin CGL2. PLoS Pathog 2010, 6(1):e1000717

36. Chen $\mathrm{H}$, Kovalchuk A, Kerio S, Asiegbu FO: Distribution and bioinformatic analysis of the cerato-platanin protein family in Dikarya. Mycologia 2013 105(6):1479-1488.

37. Gaderer R, Bonazza K, Seidl-Seiboth V: Cerato-platanins: a fungal protein family with intriguing properties and application potential. Appl Microbiol Biotechnol 2014, 98(11):4795-4803.

38. Petit L, Maier E, Gibert M, Popoff MR, Benz R: Clostridium perfringens epsilon toxin induces a rapid change of cell membrane permeability to ions and forms channels in artificial lipid bilayers. J Biol Chem 2001, 276(19):15736-15740.

39. Degiacomi MT, lacovache I, Pernot L, Chami M, Kudryashev M, Stahlberg H, van der Goot FG, Dal Peraro M: Molecular assembly of the aerolysin pore reveals a swirling membrane-insertion mechanism. Nat Chem Biol 2013, 9(10):623-629.

40. Kunzler M, Bleuler-Martinez S, Butschi A, Garbani M, Luthy P, Hengartner $\mathrm{MO}$, Aebi M: Biotoxicity assays for fruiting body lectins and other cytoplasmic proteins. Methods Enzymol 2010, 480:141-150.

41. Bayram O, Braus $\mathrm{GH}$ : Coordination of secondary metabolism and development in fungi: the velvet family of regulatory proteins. FEMS Microbiol Rev 2012, 36(1):1-24.

42. Krijgsheld P, Bleichrodt R, van Veluw GJ, Wang F, Muller WH, Dijksterhuis J, Wosten HA: Development in Aspergillus. Stud Mycol 2013, 74(1):1-29.

43. Ohm RA, de Jong JF, Lugones LG, Aerts A, Kothe E, Stajich JE, de Vries RP, Record E, Levasseur A, Baker SE, Bartholomew KA, Coutinho PM, Erdmann S, Fowler TJ, Gathman AC, Lombard V, Henrissat B, Knabe N, Kües U, Lilly WW, Lindquist E, Lucas S, Magnuson JK, Piumi F, Raudaskoski M, Salamov A, Schmutz J, Schwarze FW, vanKuyk PA, Horton JS, et al: Genome sequence of the model mushroom Schizophyllum commune. Nat Biotechnol 2010, 28(9):957-963.

44. Martin F, Aerts A, Ahrén D, Brun A, Danchin EG, Duchaussoy F, Gibon J, Kohler A, Lindquist E, Pereda V, Salamov A, Shapiro HJ, Wuyts J, Blaudez D, Buée M, Brokstein P, Canbäck B, Cohen D, Courty PE, Coutinho PM, Delaruelle C, Detter JC, Deveau A, DiFazio S, Duplessis S, Fraissinet-Tachet L, Lucic E, Frey-Klett P, Fourrey C, Feussner I, et al: The genome of Laccaria bicolor provides insights into mycorrhizal symbiosis. Nature 2008, 452(7183):88-92.

45. Kwon NJ, Garzia A, Espeso EA, Ugalde U, Yu JH: FlbC is a putative nuclear $\mathrm{C} 2 \mathrm{H} 2$ transcription factor regulating development in Aspergillus nidulans. Mol Microbiol 2010, 77(5):1203-1219.

46. Ohm RA, Aerts D, Wosten HA, Lugones LG: The blue light receptor complex WC-1/2 of Schizophyllum commune is involved in mushroom formation and protection against phototoxicity. Environ Microbiol 2013, 15(3):943-955

47. Ohm RA, de Jong JF, de Bekker C, Wosten HA, Lugones LG: Transcription factor genes of Schizophyllum commune involved in regulation of mushroom formation. Mol Microbiol 2011, 81(6):1433-1445.

48. Wang M, Gu B, Huang J, Jiang S, Chen Y, Yin Y, Pan Y, Yu G, Li Y, Wong BH Liang $Y$, Sun $H$ : Transcriptome and proteome exploration to provide a resource for the study of Agrocybe aegerita. PLoS One 2013, 8(2):e56686.

49. Yin $Y, Y u G$, Chen $Y$, Jiang $S$, Wang $M$, Jin $Y$, Lan $X$, Liang $Y$, Sun $H$ : Genome-wide transcriptome and proteome analysis on different developmental stages of Cordyceps militaris. PLOS One 2012, 7(12):e51853.

50. $Y u$ GJ, Wang $M$, Huang J, Yin $Y L$, Chen $Y$ J, Jiang $S$, Jin $Y X$, Lan $X Q$, Wong $B H$, Liang $Y$, Sun $H$ : Deep insight into the Ganoderma lucidum by comprehensive analysis of its transcriptome. PLoS One 2012, 7(8):e44031.

51. Borde V, Robine N, Lin W, Bonfils S, Geli V, Nicolas A: Histone H3 lysine 4 trimethylation marks meiotic recombination initiation sites. EMBO J 2009, 28(2):99-111.

52. Boulianne RP, Liu Y, Aebi M, Lu BC, Kues U: Fruiting body development in Coprinus cinereus: regulated expression of two galectins secreted by a non-classical pathway. Microbiology 2000, 146(Pt 8):1841-1853.

53. Thanabalu T, Porter AG: A Bacillus sphaericus gene encoding a novel type of mosquitocidal toxin of $31.8 \mathrm{kDa}$. Gene 1996, 170(1):85-89.

54. Ahmed YL, Gerke J, Park HS, Bayram Ö, Neumann P, Ni M, Dickmanns A, Kim SC, Yu JH, Braus GH, Ficner R, Ahmed YL, Gerke J, Park HS, Bayram O, Neumann P, Ni M, Dickmanns A, Kim SC, Yu JH, Braus GH, Ficner R: The 
Velvet Family of Fungal Regulators Contains a DNA-Binding Domain Structurally Similar to NF-kappaB. PLoS Biol 2013, 11(12):e1001750.

55. Vienken K, Scherer M, Fischer R: The Zn (II)2Cys6 putative Aspergillus nidulans transcription factor repressor of sexual development inhibits sexual development under low-carbon conditions and in submersed culture. Genetics 2005, 169(2):619-630.

56. Xu F, Park MR, Kitazumi A, Herath V, Mohanty B, Yun SJ, de los Reyes BG: Cis-regulatory signatures of orthologous stress-associated bZIP transcription factors from rice, sorghum and Arabidopsis based on phylogenetic footprints. BMC Genomics 2012, 13:497.

57. Traeger S, Altegoer F, Freitag M, Gabaldon T, Kempken F, Kumar A Marcet-Houben M, Poggeler S, Stajich JE, Nowrousian M: The Genome and Development-Dependent Transcriptomes of Pyronema confluens: A Window into Fungal Evolution. PLoS Genet 2013, 9(9):e1003820.

58. Clark NL, Aagaard JE, Swanson WJ: Evolution of reproductive proteins from animals and plants. Reproduction 2006, 131(1):11-22.

59. Swanson WJ, Vacquier VD: The rapid evolution of reproductive proteins. Nat Rev Genet 2002, 3(2):137-144.

60. Romero IG, Ruvinsky I, Gilad Y: Comparative studies of gene expression and the evolution of gene regulation. Nat Rev Genet 2012, 13(7):505-516.

61. Harigaya Y, Tanaka H, Yamanaka S, Tanaka K, Watanabe Y, Tsutsumi C, Chikashige Y, Hiraoka Y, Yamashita A, Yamamoto M: Selective elimination of messenger RNA prevents an incidence of untimely meiosis. Nature 2006, 442(7098):45-50.

62. Kaur J, Sebastian J, Siddiqi I: The Arabidopsis-mei2-like genes play a role in meiosis and vegetative growth in Arabidopsis. Plant Cell 2006, 18(3):545-559.

63. Merino ST, Cummings WJ, Acharya SN, Zolan ME: Replication-dependent early meiotic requirement for Spo11 and Rad50. Proc Natl Acad Sci U S A 2000, 97(19):10477-10482.

64. Diz AP, Martinez-Fernandez M, Rolan-Alvarez E: Proteomics in evolutionary ecology: linking the genotype with the phenotype. Mol Ecol 2012, 21(5):1060-1080

65. Walti MA, Villalba C, Buser RM, Grunler A, Aebi M, Kunzler M: Targeted gene silencing in the model mushroom Coprinopsis cinerea (Coprinus cinereus) by expression of homologous hairpin RNAs. Eukaryot Cell 2006, 5(4):732-744.

66. Swamy S, Uno I, Ishikawa T: Morphogenic Effects of Mutations at the A and B Incompatibility Factors in Coprinus cinereus. J Gen Microbiol 1984, 130:6.

67. Ramakers C, Ruijter JM, Deprez RH, Moorman AF: Assumption-free analysis of quantitative real-time polymerase chain reaction (PCR) data. Neurosci Lett 2003, 339(1):62-66.

68. Schefe JH, Lehmann KE, Buschmann IR, Unger T, Funke-Kaiser H: Quantitative real-time RT-PCR data analysis: current concepts and the novel "gene expression's CT difference" formula. J Mol Med (Berl) 2006, 84(11):901-910.

69. Aursnes IA, Rishovd AL, Karlsen HE, Gjoen T: Validation of reference genes for quantitative RT-qPCR studies of gene expression in Atlantic cod (Gadus morhua I.) during temperature stress. BMC Res Notes 2011, 4:104.

70. de Oliveira LA, Breton MC, Bastolla FM, Camargo Sda S, Margis R, Frazzon J, Pasquali G: Reference genes for the normalization of gene expression in eucalyptus species. Plant Cell Physiol 2012, 53(2):405-422.

71. Ferreira $\mathrm{E}$, Cronje MJ: Selection of suitable reference genes for quantitative real-time PCR in apoptosis-induced MCF-7 breast cancer cells. Mol Biotechnol 2012, 50(2):121-128.

72. Huggett J, Dheda K, Bustin S, Zumla A: Real-time RT-PCR normalisation; strategies and considerations. Genes Immun 2005, 6(4):279-284.

73. Langnaese K, John R, Schweizer H, Ebmeyer U, Keilhoff G: Selection of reference genes for quantitative real-time PCR in a rat asphyxial cardiac arrest model. BMC Mol Biol 2008, 9:53.

74. Silveira ED, Alves-Ferreira M, Guimaraes LA, da Silva FR, Carneiro VT: Selection of reference genes for quantitative real-time PCR expression studies in the apomictic and sexual grass Brachiaria brizantha. BMC Plant Biol 2009, 9:84

75. Wan H, Yuan W, Ruan M, Ye Q, Wang R, Li Z, Zhou G, Yao Z, Zhao J, Liu S, Yang $Y$ : Identification of reference genes for reverse transcription quantitative real-time PCR normalization in pepper (Capsicum annuum L.). Biochem Biophys Res Commun 2011, 416(1-2):24-30.

76. Trapnell C, Williams BA, Pertea G, Mortazavi A, Kwan G, van Baren MJ, Salzberg SL, Wold BJ, Pachter L: Transcript assembly and quantification by RNA-Seq reveals unannotated transcripts and isoform switching during cell differentiation. Nat Biotechnol 2010, 28(5):511-515.
77. Tarazona S, Garcia-Alcalde F, Dopazo J, Ferrer A, Conesa A: Differential expression in RNA-seq: a matter of depth. Genome Res 2011, 21(12):2213-2223.

78. Robinson MD, McCarthy DJ, Smyth GK: edgeR: a Bioconductor package for differential expression analysis of digital gene expression data. Bioinformatics 2010, 26(1):139-140.

79. Altschul SF, Madden TL, Schaffer AA, Zhang J, Zhang Z, Miller W, Lipman DJ: Gapped BLAST and PSI-BLAST: a new generation of protein database search programs. Nucleic Acids Res 1997, 25(17):3389-3402.

80. Petersen TN, Brunak S, von Heijne G, Nielsen H: SignalP 4.0: discriminating signal peptides from transmembrane regions. Nat Methods 2011, 8(10):785-786.

81. Sonnhammer EL, von Heijne G, Krogh A: A hidden Markov model for predicting transmembrane helices in protein sequences. Proc Int Conf Intell Syst Mol Biol 1998, 6:175-182.

82. Nguyen Ba AN, Pogoutse A, Provart N, Moses AM: NLStradamus: a simple Hidden Markov Model for nuclear localization signal prediction. BMC Bioinformatics 2009, 10:202.

83. Eisen MB, Spellman PT, Brown PO, Botstein D: Cluster analysis and display of genome-wide expression patterns. Proc Natl Acad Sci U S A 1998, 95(25):14863-14868.

84. Thompson JD, Higgins DG, Gibson TJ: CLUSTAL W: improving the sensitivity of progressive multiple sequence alignment through sequence weighting, position-specific gap penalties and weight matrix choice. Nucleic Acids Res 1994, 22(22):4673-4680

85. Letunic I, Doerks T, Bork P: SMART 7: recent updates to the protein domain annotation resource. Nucleic Acids Res 2012, 40(Database issue):D302-D305.

86. Wisniewski JR, Zougman A, Nagaraj N, Mann M: Universal sample preparation method for proteome analysis. Nat Methods 2009, 6(5):359-362.

doi:10.1186/1471-2164-15-492

Cite this article as: Plaza et al: Comparative transcriptomics of the model mushroom Coprinopsis cinerea reveals tissue-specific armories and a conserved circuitry for sexual development. BMC Genomics 2014 15:492.

\section{Submit your next manuscript to BioMed Central and take full advantage of:}

- Convenient online submission

- Thorough peer review

- No space constraints or color figure charges

- Immediate publication on acceptance

- Inclusion in PubMed, CAS, Scopus and Google Scholar

- Research which is freely available for redistribution 